Review

\title{
A Review of AlGaN-Based Deep-Ultraviolet Light-Emitting Diodes on Sapphire
}

\author{
Yosuke Nagasawa and Akira Hirano * \\ UV Craftory Co., Ltd., 2-305, Fujimidai 2-7-2, Chikusa, Nagoya 464-0015, Japan; ynagasawa@uvcr.jp \\ * Correspondence: hirano@uvcr.jp; Tel.: +81-52-861-3505
}

Received: 15 June 2018; Accepted: 19 July 2018; Published: 31 July 2018

check for updates

Featured Application: Sterilization, UV curing and printing, and phototherapy.

\begin{abstract}
This paper reviews the progress of AlGaN-based deep-ultraviolet (DUV) light emitting diodes (LEDs), mainly focusing in the work of the authors' group. The background to the development of the current device structure on sapphire is described and the reason for using a (0001) sapphire with a miscut angle of $1.0^{\circ}$ relative to the m-axis is clarified. Our LEDs incorporate uneven quantum wells (QWs) grown on an AlN template with dense macrosteps. Due to the low threading dislocation density of AlGaN and AlN templates of about $5 \times 10^{8} / \mathrm{cm}^{2}$, the number of nonradiative recombination centers is decreased. In addition, the uneven QW show high external quantum efficiency (EQE) and wall-plug efficiency, which are considered to be boosted by the increased internal quantum efficiency (IQE) by enhancing carrier localization adjacent to macrosteps. The achieved LED performance is considered to be sufficient for practical applications. The advantage of the uneven QW is discussed in terms of the EQE and IQE. A DUV-LED die with an output of over $100 \mathrm{~mW}$ at $280-300 \mathrm{~nm}$ is considered feasible by applying techniques including the encapsulation. In addition, the fundamental achievements of various groups are reviewed for the future improvements of AlGaN-based DUV-LEDs. Finally, the applications of DUV-LEDs are described from an industrial viewpoint. The demonstrations of $\mathrm{W} / \mathrm{cm}^{2}$-class irradiation modules are shown for UV curing.
\end{abstract}

Keywords: AlGaN; nitride; deep-ultraviolet; light emitting diode; DUV; LED; sapphire; sterilization; UV curing; UV printer

\section{Introduction}

\subsection{General Overview}

AlGaN ternary alloy has a direct bandgap tunable between $3.43 \mathrm{eV}$ and $6.11 \mathrm{eV}$ and is suitable for the fabrication of optical devices with a wavelength range between about $200 \mathrm{~nm}$ and $365 \mathrm{~nm}$. In this wavelength range, applications include sterilization [1-4], ultraviolet (UV) curing and printing [5,6], phototherapy and medical applications $[7,8]$, deodorization by the use of a photocatalyst $[9,10]$, and sensing applications for materials such as urea [11,12]. To date, these applications mainly involve the use of mercury-based lamps. The Minamata Convention on Mercury took effect on 16 August 2017, and AlGaN-based light-emitting diodes (LEDs) are expected to be used as an alternative to mercury lamps. The authors' group has reported AlGaN-based deep-ultraviolet (DUV) LED bare dies with external quantum efficiencies (EQEs) of $3.5 \%$ at $265 \mathrm{~nm}$, over $4.5 \%$ at $270 \mathrm{~nm}$, and over $6 \%$ between $280 \mathrm{~nm}$ and $300 \mathrm{~nm}$ without encapsulation and with a p-GaN contact layer [13]. These EQEs correspond to high wall-plug-efficiencies (WPEs) due to the low turn-on voltage $\left(\mathrm{V}_{\mathrm{f}}\right)$ of $5-6 \mathrm{~V}$ at $100 \mathrm{~mA}\left(31 \mathrm{~A} / \mathrm{cm}^{2}\right.$ at the junction area on $1 \times 1 \mathrm{~mm}^{2}$ dies). The recorded WPEs of bare dies at $100 \mathrm{~mA}$ were $2.7 \%$, $3.1 \%, 4.4 \%$, and $4.3 \%$ at $266 \mathrm{~nm}, 271 \mathrm{~nm}, 281 \mathrm{~nm}$, and $298 \mathrm{~nm}$, respectively, and the peak WPEs of 
the 281 and $298 \mathrm{~nm}$ LEDs exceeded 5\%. When similar DUV-LEDs in Ref. [13] were mounted on the commercialized packages, a lifetime of more than $10,000 \mathrm{~h}$ was achieved. If encapsulation is assumed to be used, the WPEs are expected to be improved 1.5-fold [14,15] and the WPEs are predicted to be $4.1 \%, 4.7 \%, 6.6 \%$, and $6.5 \%$, respectively, for $100 \mathrm{~mA}$ operation. These values are significantly greater than those of 2-3\% for incandescent lamps. The WPEs of high- or ultrahigh-pressure mercury lamps are in the range of $10-15 \%$ over their entire spectra. Since UV applications often do not utilize all the spectral light of UV bulbs, the utilization factor should be considered; thus, these performances indicate that conventional mercury lamps can be replaced with such LEDs. The lifetimes of high- and ultrahigh-pressure mercury lamps are normally in the range of 100-2000 h, clearly illustrating the advantages of DUV-LEDs with lifetimes of over 10,000 h.

The trend of the EQE dependence on the wavelength is shown in Figure 1. Note that all the EQEs in Figure 1 were achieved for simple devices fabricated with a $\mathrm{p}-\mathrm{GaN}$ contact layer opaque to DUV $(\lambda<300 \mathrm{~nm})$ and without any reflective electrodes. DUV-LEDs with wavelength between $280 \mathrm{~nm}$ and $300 \mathrm{~nm}$ are considered to be suitable for obtaining higher EQEs and WPEs. The collection of published EQE values without distinguishing the incorporated features such as reflective electrodes [16] shows a similar trend to that in Figure 1. Figure 2 illustrates the LEDs demonstrated by the authors' group. These samples also have a thick $\mathrm{p}-\mathrm{GaN}$ contact layer.

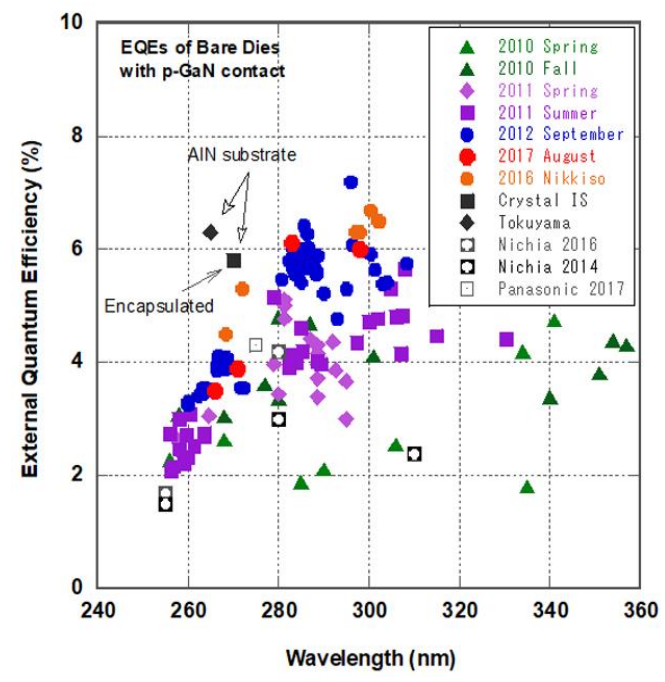

Figure 1. EQE mapping of AlGaN-based LED dies with p-GaN contact layer. The data are mainly for LED dies on planar sapphire from our group (colored). EQEs of LED dies from elsewhere (uncolored) using AlN substrates [17,18] and sapphire substrates [19-21] with a p-GaN contact layer are also shown. Solid uncolored symbols indicate the use of an AlN bulk substrate, where " $\mathbf{\square}$ " indicates with encapsulation [17] and " $\bullet$ " indicates no encapsulation. The EQEs in the case of an AlN substrate

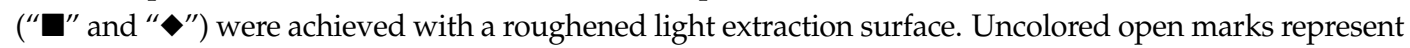
LED dies with $\mathrm{p}$-GaN layer fabricated on planar sapphire reported by other groups. All of our data (colored) were obtained without boosting light extraction efficiency (LEE) using encapsulation [14,15,17] or a sapphire lens [21].

The characteristic strong spectral peaks of mercury are located at $365 \mathrm{~nm}$ (i-line) and $253.7 \mathrm{~nm}$ (sterilization line). One of the advantages of AlGaN-based LEDs is their brightness in the region where bright lines from mercury lamps are lacking. In addition, the tunable wavelength of AlGaN-based LEDs is considered to be highly suitable for sensing applications, which are the most accessible applications for DUV-LEDs in their early stage of development. However, the WPE of low-pressure mercury lamps exceeds $25 \%$. In addition, about $90 \%$ of the emitted light from low-pressure mercury lamps is sterilization line. Sterilization is currently considered to be a difficult application for DUV-LEDs when considering only WPE and the production cost. For example, a concept of intermittent lighting 
is necessary for applying DUV-LEDs to sterilization, because the bacteria do not increase soon after sterilization procedure.

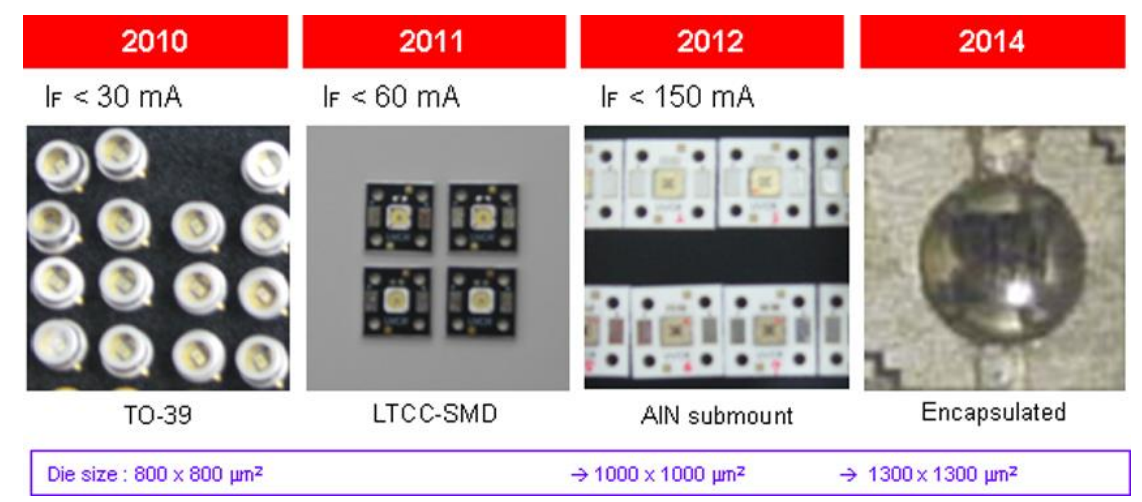

Figure 2. Demonstration samples of DUV-LEDs fabricated by UV Craftory Co., Ltd. Until 2014, the effect of the miscut angle of sapphire [13] was studied to increase EQE. In parallel, the heat dissipation was improved and the chip size was increased to obtain higher output power. A thick p-GaN layer is considered to be necessary to obtain a longer lifetime and to reduce device faults. Since 2012, resin encapsulation using fluorine polymers has been intensively investigated [14] to increase the extracted electroluminescence (EL). (Photographs are permitted to be reused from Oyobutsuri [22] (in Japanese). (C) Japan Society Applied Physics.).

\subsection{Outlines and Objective of This Review}

One of the objectives of this review is to compare various techniques to fabricate DUV-LEDs and clarify the reasons for our choices, including the use of high-miscut sapphire. The reports on DUV-LEDs from different groups mainly evaluated the LED performances using their own techniques. The discussion cross-linking papers from different groups or from the same group including our group is considered to be lacking, similar to the situation at the beginning of InGaN research. We aim to link the studies of various groups related to AlGaN-based DUV-LEDs despite their limited disclosure due to business and patent strategies. We also comment on how our independent results helped to determine our current device structure.

Following this section, the main approaches to obtaining AlN for the growth of AlGaN device layers are categorized in Section 2. The factors determining crystal quality of AlGaN on AlN are explained in Section 3. In the past, a conventional AlN template grown on sapphire within a reasonable growth time [23] had a threading dislocation density (TDD) on the order of $10^{9} / \mathrm{cm}^{2}$, which was not sufficiently low. The improvement of TDD was a priority issue to be solved. In Section 4, the techniques for growing AlN with an improved TDD on the order of $10^{8} / \mathrm{cm}^{2}$ on sapphire are compared. The reason for using high-miscut sapphire is partially clarified by discussion of the TDD, growth time, and growth temperature. In addition to epitaxial growth, the constitution and techniques necessary to fabricate our current LEDs are explained in Sections 5-7. Section 8 describes the packaging required for fabrication of DUV-LEDs. In Section 9, a factor to be considered when measuring the DUV output is briefly given. Following Section 10, where the device layers are clarified, Sections 11-14 describe the performance of the DUV-LEDs with novel QWs. The expected performance of our dies in the near future upon improving the LEE is written in Section 15. From the viewpoint of the long-term future, the frontiers of DUV-LEDs are introduced showing the challenges by the various groups to improve DUV-LEDs in Section 16. Then, the application and the demonstration of irradiation modules are outlined in Section 17.

\section{Groups Manufacturing AlGaN-Based DUV-LEDs}

Currently, there are many groups manufacturing AlGaN-based near-ultraviolet (NUV: $300 \mathrm{~nm}<$ $\lambda<400 \mathrm{~nm}$, about 300-350 nm for AlGaN devices) and DUV (200 nm $<\lambda<300 \mathrm{~nm})$ LEDs. The groups can 
be distinguished into AlN bulk and sapphire groups according to the substrate. Mergers and alliances often occur in science ventures, and the owner of the intellectual properties and the manufacturer are often different. To our best knowledge, the major players can be grouped as shown in Table 1, which is used to clarify the trends of research and development.

Table 1. List of research, development and manufacturing groups of AlGaN-based DUV-LEDs, indicating the substrate type, the growth technique, and related techniques. EM, enhanced migration; CHT, continuous high-temperature growth by metal organic chemical vapor deposition (MOCVD); + HVPE, halide vapor phase epitaxy. $+\mathrm{R}$ and +LLO indicate roughening and laser liftoff, used as additional techniques, respectively.

\begin{tabular}{|c|c|c|c|c|c|}
\hline Root of Science Venture & Start Up Company & Large Company or Alliance Partners & Substrate & Option & Refs. \\
\hline $\begin{array}{c}\text { RPI }^{1} \\
\text { Univ. South Carolina }\end{array}$ & $\begin{array}{l}\text { SETi } \\
\text { Nitek }\end{array}$ & Seoul Viosys ${ }^{(\mathrm{KR})}$ & Sapphire & EM & [24-28] \\
\hline RPI $^{1}$ & Crystal IS & Asahi Kasei $^{(\mathrm{JP})}$ & AlN & $+\mathrm{R}$ & {$[17,29]$} \\
\hline \multirow[t]{2}{*}{ North Carolina State Univ. } & $\begin{array}{l}\text { Hexatech } \\
\text { Adroit }\end{array}$ & Tokuyama $^{(\mathrm{IP})} \rightarrow{ }^{3}$ Stanley $(\mathrm{IP})$ & AlN & $\begin{array}{c}+\mathrm{HVPE} \\
+\mathrm{R}\end{array}$ & {$[18,30]$} \\
\hline & Rayvio & & Sapphire & & \\
\hline $\begin{array}{l}\text { Nagoya Univ. } \\
\text { Meijo Univ. }\end{array}$ & UV Craftory & Nikkiso ${ }^{(\mathrm{PP})}+\mathrm{FPG}^{(\mathrm{TW})}$ & Sapphire & CHT & {$[13,31-40]$} \\
\hline \multirow[t]{3}{*}{ RIKEN } & & $\begin{array}{l}\text { NGK }^{(\mathrm{JP})} \rightarrow{ }^{3} \text { Dowa }^{(\mathrm{JP})} \\
\text { Panasonic } \\
\end{array}$ & Sapphire & EM & {$[19,41-45]$} \\
\hline & & Nichia $^{(J P)}$ & Sapphire & & {$[20,21,46]$} \\
\hline & & Toyoda Gosei( ${ }^{(P)}$ & Sapphire & & \\
\hline \multirow[t]{6}{*}{$\begin{array}{c}\text { FBH }^{2} \\
\text { TU Berlin }\end{array}$} & UV Photonics & & & & {$[47-49]$} \\
\hline & & Siemens $A G^{\mathrm{DE})}$ & & & \\
\hline & Bioraytron & $\mathrm{HPL}^{(\mathrm{TW})}+$ Epileds $^{(\mathrm{TW})}$ & Sapphire & & \\
\hline & & LG Innotek ${ }^{(\mathrm{KR})}$ & Sapphire & $+\mathrm{LLO}$ & [50] \\
\hline & & Samsung ${ }^{(\mathrm{KR})}$ & Sapphire & & {$[51,52]$} \\
\hline & & QD Jason $(\mathrm{CN})$ & Sapphire & EM & {$[53,54]$} \\
\hline
\end{tabular}

${ }^{1}$ PRI, Rensselaer Polytechnic Institute; ${ }^{2}$ FBH, Ferdinand Braun Institut, ${ }^{3} \rightarrow$, Business transfer.

The groups employing AlN bulk substrates have mainly followed two approaches to fabricating AlGaN-based LEDs. The problem in growing AlN substrates by physical vapor transport (PVT) [55], which is also referred to as sublimation [56,57], is absorption in the UV region due to carbon [58] and oxygen [59] impurities. The advantage of AlN bulk substrates is high crystallinity with a TDD lower than $10^{4} / \mathrm{cm}^{2}[55,56]$. Normally, dislocations are considered to be related to nonradiative recombination centers (NRCs). Based on this superficial understanding, the advantage of using AlN substrates is expected to result in a higher internal quantum efficiency (IQE) [60,61].

It is conventionally considered that high crystal quality contributes to increased reliability [30,62]. However, nitride materials are robust and InGaN-based LEDs [63-66] and LDs [67,68] with high TDDs of $10^{9} / \mathrm{cm}^{2}$ and $10^{6} / \mathrm{cm}^{2}$, respectively, have been commercialized. According to the experimental data in Figure 1 for AlGaN-based DUV-LEDs, the EQEs of LEDs on a sapphire substrate are comparable to those on an AlN substrate with TDD of less than $10^{6} / \mathrm{cm}^{2}$. The crystal quality required for AlGaN-based DUV-LEDs will be discussed and partially clarified in this paper.

The groups employing sapphire substrates can be roughly categorized in two subgroups: those attempting enhanced migration (EM) $[23,53,69-71]$ by applying an alternating or pulsed supply of source precursors and us focusing on continuous high-temperature (CHT) growth [13,31-40]. Compared with GaN, mass transportation of AlN during the growth is very small and EM and $\mathrm{CHT}$ growth were investigated to recover the lack of mass transport. For the EM technique, the growth mechanism is similar to atomic-layer epitaxy, and the growth technique was first called as pulsed atomic-layer epitaxy (PALE) [23]. Improvements were then carried out by the 
following methods. Migration-enhanced MOCVD (MEMCVD) [25], ammonia pulse-flow method [70], and migration-enhanced epitaxy (MEE) [71] are based on a similar concept and their growth temperatures are generally lower than that required for continuous growth $[31,72,73]$. The problem with the EM technique from the industrial viewpoint is its slow growth rate. A growth rate of $0.6 \mu \mathrm{m} / \mathrm{h}[70]$ has been reported for EM, and the low growth rate is considered to be an intrinsic nature of the atomic-layer-like epitaxy. To overcome the lack of mass transport for AlN growth, CHT growth was attempted by increasing the growth temperature greater than $1300{ }^{\circ} \mathrm{C}$. The growth rate in this case of continuous growth has been reported to be higher than $5 \mu \mathrm{m} / \mathrm{h}$ [34,72], enabling epitaxial lateral overgrowth (ELO) [31,73], the use of a patterned sapphire substrate (PSS) [39], and the thick AlN growth within a growth time of several hours. However, the problems of $\mathrm{CHT}$ growth were a large run-to-run fluctuation of growth machine and a short lifetime of waste parts inside the growth chamber, which must be solved for the mass production of DUV-LEDs.

Recently, a new approach to the fabrication of AlN templates on sapphire substrate has been demonstrated [74-76]. The crystallinity of a thin AlN film as deposited on sapphire by sputtering can be improved by annealing at over $1500{ }^{\circ} \mathrm{C}$. AlGaN-based NUV- $(\lambda=350 \mathrm{~nm})$ and DUV-LEDs $(\lambda=268 \mathrm{~nm})$ have been demonstrated [47] using this new AlN templates. Currently, there are three main approaches to fabricating AlN templates on sapphire.

\section{Crystal Quality of AlGaN on AlN}

The TDD has a strong relationship with NRCs [77] for AlGaN QWs. To clarify the crystal quality required for AlN, the AlGaN QWs and n-AlGaN cladding layer must be discussed together. The EQEs of bare die LEDs on sapphire and AlN bulk substrates in Figure 1 do not substantially differ. It has been claimed that $2 \times 10^{8} / \mathrm{cm}^{2}$ is good enough to obtain a satisfactory IQE [24,41] for the flat QWs, showing AlN bulk substrate with TDD of less than $10^{6} / \mathrm{cm}^{2}$ is over quality. However, the AlN template with TDD on the order of $10^{8} / \mathrm{cm}^{2}$ to grow AlGaN LED layers was difficult to be fabricated on sapphire. In addition, misfit dislocations at the interface with AlN between AlGaN layer increased the TDD of the n-AlGaN cladding layer $[78,79]$ in the case of using AlN bulk substrate with the TDD of less than $10^{6} / \mathrm{cm}^{2}$, showing that $\mathrm{n}-\mathrm{Al}_{0.5} \mathrm{Ga}_{0.5} \mathrm{~N}$ cladding layers exhibited (10-12) and (0002) $\omega$-scan X-ray rocking curves (XRCs) with full-width-half-maximum (FWHM) of greater than 600 arcs and 200 arcs, respectively [80]. Except in the case of AlGaN with a high AlN content, the TDD of n-AlGaN layer on AlN or AlN templates is considered to be limited to the order of $10^{8} / \mathrm{cm}^{2}$ when AlGaN is grown on a planer AlN surface.

The required crystal quality should be discussed on the basis of point defects at the AlGaN QWs as well as the TDD. When the crystal quality is moderately improved, NRCs derived from point defects must be considered [81] because $\mathrm{Al}$ vacancies $\left(\mathrm{V}_{\mathrm{Al}}\right)$ have been revealed to be NRCs in AlGaN QWs [82]. Carrier localization has been clarified to be the reason why GaN with a high TDD of between $10^{8} / \mathrm{cm}^{2}$ and $10^{9} / \mathrm{cm}^{2}$ enables the mass production of InGaN-LEDs [83-85]. Similarly, AlGaN-LEDs are considered to involve the carrier localization effect [86-89]. The effects of $\mathrm{V}_{\mathrm{Al}}$ on IQE have been observed using samples with TDDs on the order of $10^{9} / \mathrm{cm}^{2}$ [90].

Until about 2005, AlN on sapphire showed insufficient crystallinity to enable the growth of AlGaN LEDs, making it impossible to realize the practical efficiencies. The difficulty of improving AlGaN quality when AlN crystallinity is insufficient is due to crystal improvement mechanisms such as three-dimensional growth are not expected for $\mathrm{AlGaN}$ on AlN. Attempts to overcome this problem to obtain AlN with a moderate TDD on the order of $10^{8} / \mathrm{cm}^{2}$ on sapphire substrate are described in the following.

\section{Attempted Improvements of AlN on Sapphire to Obtain TDD Less Than $10^{9} / \mathrm{cm}^{2}$}

\subsection{Epitaxial Lateral Overgrowth (ELO) and Patterned Sapphire Substrate (PSS)}

GaN improvement techniques are briefly introduced as a contrast to those for AlN. The low-temperature (LT) buffer layer technique [91,92] has enabled a GaN film with a TDD of less 
than $10^{9} / \mathrm{cm}^{2}$ to be produced on sapphire. The additional technique to improving GaN on LT buffer layer on sapphire is well known as ELO, and a GaN with a TDD of lower than $10^{7} / \mathrm{cm}^{2}$ successfully led to demonstrate laser diodes (LDs) [68,92]. The variations of crystal improvement techniques has been attempted for GaN on LT buffer, including pendeoepitaxy [93] and facet-controlled ELO [94], which involve the masking of dislocations and utilizing the mass transfer of $\mathrm{GaN}$. In addition, the use of a PSS gives a TDD on the order of $10^{8} / \mathrm{cm}^{2}[95,96]$; PSS technique utilizes the decomposition of irregularly oriented GaN seed crystals on sapphire. GaN substrates with TDD of lower than $10^{6} / \mathrm{cm}^{2}$ are currently used for the production of LDs, and ELO-GaN has been replaced by GaN substrates $[97,98]$ to produce LDs. Despite the smaller improvement of GaN for PSSs, only the PSS technique is used to produce commercialized InGaN-based LEDs $(<365 \mathrm{~nm})$ on sapphire owing to its moderately good crystallinity on sapphire and the simple growth procedure without regrowth and masking of dislocations.

It is reasonable to consider that $\mathrm{AlGaN}$ with moderate crystal quality is desirable for fabrication of AlGaN LEDs. AlN and GaN have a wurtzite structure and similar techniques are expected to be effective for improving AlN. Similar to GaN, improvements of AlN and AlGaN using ELO and PSS have been attempted because TDD on the order of $10^{9} / \mathrm{cm}^{2}$ is too high to obtain high IQEs [69,99]. With this background, the ELO of AIN on a PSS using trenched sapphire has been investigated $[33,100,101]$. The AlN crystallinity was reported to be improved using PSSs. DUV-LEDs were fabricated using ELO on PSS [27,39], but significant increases in EQEs have not been reported. Based on our experiment [39], although AlN improvement in the TDD of $\operatorname{AlN}\left(<10^{8} / \mathrm{cm}^{2}\right)$ above the groove of sapphire was achieved, reducing the miss-coalescence of the entire wafer was difficult. The lack of mass transfer for AlN is considered to cause the difficulty. To overcome the lack of mass transfer of AlN, a nanoimprint (NIP) technique has been applied to a Si substrate, in which submicron circles were patterned [102,103]. Coalescence was observed, as were $\mu \mathrm{m}$-size PSSs. However, the crystallinity was not improved significantly. All the experiments on AlN-ELO incorporated PSS with flat tops to obtain AlN seed crystals, and the misoriented small AlN grains around the grooves were observed. The misoriented AlN seed crystals are considered to remain due to the insufficient decomposition of the irregularly oriented seed AlN crystals. In addition, there are reports that the polarity of AlN is difficult to align [104,105]. AlN is expected to behave similarly to GaN [106-108] if the growth temperature of AlN is increased much higher than $1300{ }^{\circ} \mathrm{C}$. Currently, the gap between AlN and GaN is difficult to close, and ELO and PSS techniques are unlikely to be used in practice. The coalescence faults resulted in low yield.

\subsection{Growth of Thick AlN Layer}

Compared with GaN, AlN hardly decomposes or undergoes mass transport [104,105]. Therefore, the techniques that can be used to improve crystal quality are limited. Since the quality of crystals naturally tends to improve during their growth, a method of improving the crystal quality of AlN is to grow a thick layer with a thickness of about $5 \mu \mathrm{m}[32,109]$. CHT growth at a temperature exceeding $1300{ }^{\circ} \mathrm{C}$ can reduce the growth time due to its growth rate of more than $5 \mu \mathrm{m} / \mathrm{h}$. The growth of thick layer often results in cracks due to the limitation of critical film thickness, limiting the maximum AlN thickness; thus, the thickness of AlN is considered to be limited at around $5 \mu \mathrm{m}$ in practice. The achieved FWHM values of $\omega$-scans of (0002) and (10-10) XRCs for an AlN thickness of $4.5 \mu \mathrm{m}$ were 150 and 700 arcsec, respectively, when using planar sapphire with a miscut of $0.3^{\circ}$ at a growth rate of $5.5 \mu \mathrm{m} / \mathrm{h}$ [109]. In addition, by modulating the V/III ratio for CHT growth, (0002) and (10-10) XRCs with FWHMs of 220 and 475 arcsec were obtained [110] for an AlN thickness of 3-4 $\mu \mathrm{m}$. Meanwhile, the groups employing EM have reported that thick AlN layers to obtain the AlN with a TDD of about $2 \times 10^{8} / \mathrm{cm}^{2}$ [24], which enables a high IQE of $49 \%$ for smooth and flat MQWs. A TDD of $2 \times 10^{8} / \mathrm{cm}^{2}$ was also reported by another EM group to have a high IQE [41]. Despite the growth rate of about $0.5 \mu \mathrm{m} / \mathrm{h}$ for EM, an attempt to grow thick AlN has also been reported [70] to obtain AlN with a low TDD. From the viewpoint of cost-feasible production, the growth of thick AlN layers by EM is not suitable because of the long growth time. Instead, in the early stage of development of CHT 
growth, the short lifetime of consumables, such as the heater and wafer tray, due to the high growth temperature $\left(>1300^{\circ} \mathrm{C}\right)$ were problems to be solved.

\subsection{Use of High Miscut Sapphire}

During our optimization for the miscut angle of sapphire oriented along the m-axis, the improved-AlN crystallinity was observed when changing the miscut angle from $0.3^{\circ}$ to $1.5^{\circ}$. Similar phenomenon was observed for the CHT growth of AlN. However, based on the conventional understanding that a rough surface with macrosteps, of which height gap between flat surfaces is greater than a unit cell, is unsuitable to grow LED layers on it, Mg was added to AlN with an aim of making AlN template smoother in the case of using sapphire with $0.5^{\circ}$ miscut [109]. The macrostep in this paper might include stairway structure of bunched $\mathrm{m}(10-10)-, \mathrm{r}(1-102)-$ and narrow c(0001)-surfaces.

In the past, using molecular beam epitaxy at the temperature of $700{ }^{\circ} \mathrm{C}$, an improved crystallinity of AlN was observed in the case of using sapphire with higher miscut of $1.0^{\circ}$ in addition to the exhibit of multi-atomic layer macrosteps, and the maximum miscut angle to obtain stepflow surface was reported to be $0.5^{\circ}$ [111]. Using molecular beam epitaxy, the improved (0002) and (10-12) XRCs of GaN were also observed in the case of using sapphire with higher miscut of $1.0^{\circ}$ and $2.0^{\circ}$ with the exhibit of bunched steps. The maximum miscut angle of $0.5^{\circ}$ to exhibit the stepflow surface [112] was reported. The groups using EM reported the smooth surfaces of AlN with stepflow $[71,113]$ to make LEDs. These reports indicate that the macrosteps were not expected to be useful to fabricate LEDs. Despite this general understanding that excess miscut angle cannot be suitable to fabricate LEDs due to macrosteps, not to miss the optimal angle, the investigation on a wide range of miscut angle between $0.1^{\circ}$ and $3.0^{\circ}$ was carried out. The result is shown in Figure 3. The maximum miscut angle for which a stepflow surface could be obtained was limited to below $0.3^{\circ}$. This agrees well with the results of other groups. The highest crystal quality was observed at a miscut angle of $1.5^{\circ}$. It was unexpectedly found that AlN with dense macrosteps is suitable for the fabrication of DUV-LEDs, contradicting the common understanding of QWs. In fact, the miscut angle is usually set to between $0.15^{\circ}$ and $0.3^{\circ}$ to produce InGaN LEDs with stepflow surfaces. There was indeed no evidence to indicate that AlN with macrosteps is suitable for fabrication of DUV-LEDs.

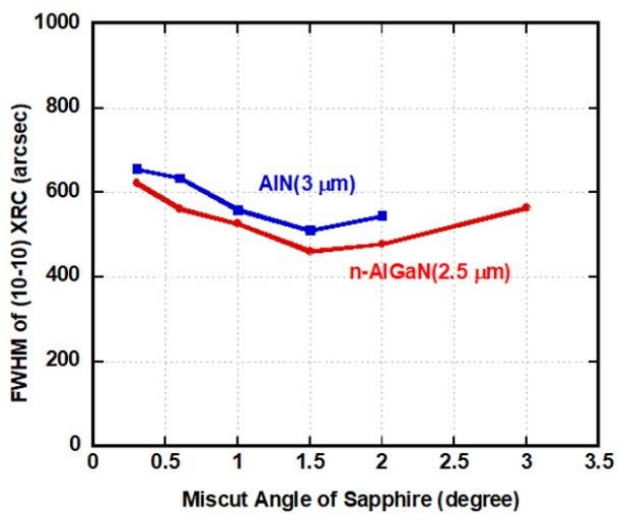

(a)

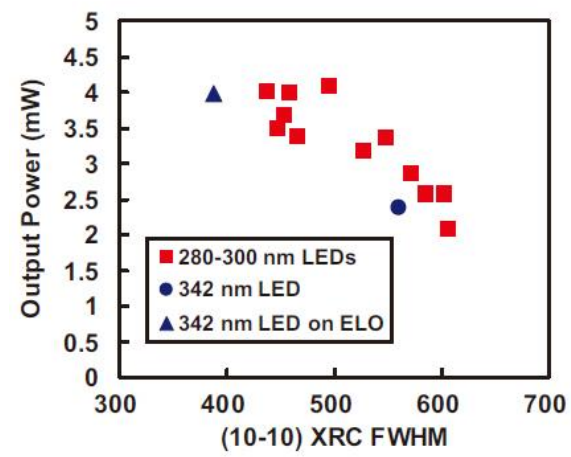

(b)

Figure 3. (a) Relationship between FWHM of XRC (10-10) for AlN and AlGaN on AlN templates and miscut angle of sapphire obtained before optimizing AlN growth recipe. (b) At that time, the (10-10) XRC of AlGaN experimentally suggested a relationship with the EL output. The relationship between the EL output and FWHM of (0002) XRC was unclear [38] at that time. The n-AlGaN cladding layers showed slightly higher crystallinity than the AlN layers. ((a) is reused from Proc. SPIE 9926, 99260C (2016); and (b) is permitted to be reused from Physica Stat. Solidi A 2011, 208, 1594-1596 (c) Wiley \& Sons, Inc.). 
Figure 3a shows the average FWHM of the (10-10) XRC of AlN templates grown on sapphire with miscut angles between $0.1^{\circ}$ and $3.0^{\circ}$. The FWHMs of (10-10) XRCs for n-AlGaN on AlN on sapphire with various miscut angles are also shown. The EL outputs of DUV-LEDs for different miscut angles reported in our articles $[13,37,38]$ are shown in Figure 4 . Figure 5 shows AFM images of our recently grown AlN templates [13] on sapphires with various miscut angles using the same growth recipe. After recipe optimization along with the increased EL, steps had unexpectedly appeared for all sapphire substrates with various miscut angles. Fortunately, AlN templates with macrosteps have been proven to be useful for producing AlGaN-based DUV-LEDs with superior performance to those grown on flat AlN.

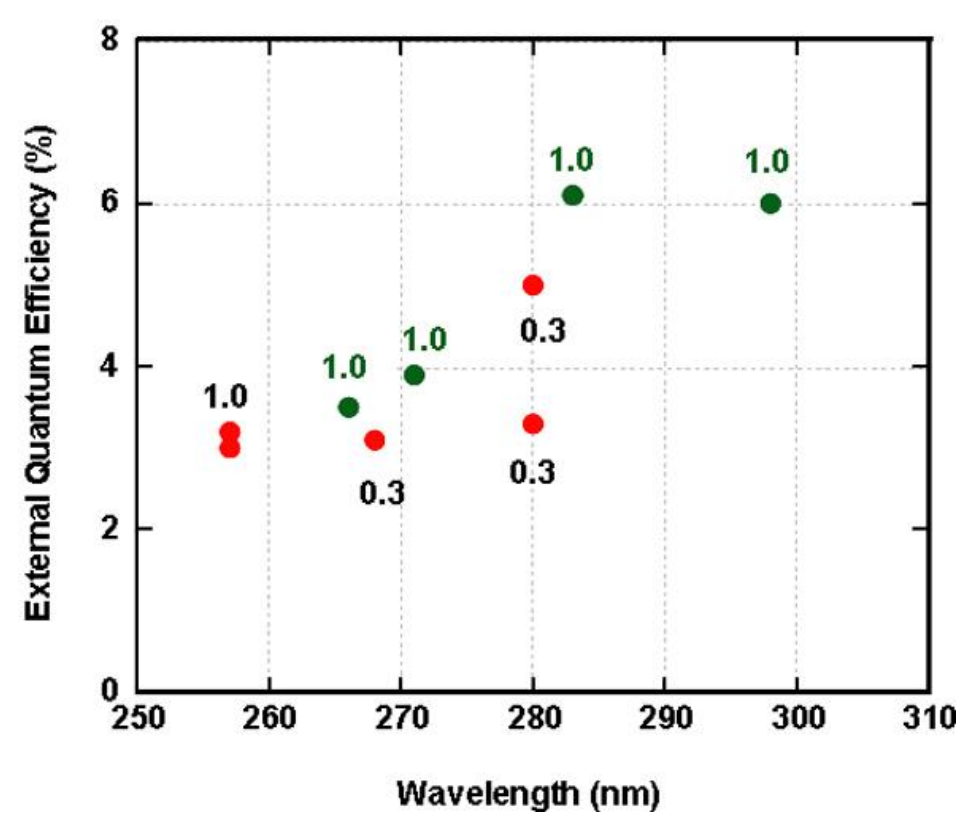

Figure 4. Our reported EQEs $[13,37,38]$ for various miscut angles of the sapphire substrate. The EL output tends to increase in the case of using high-miscut sapphire. (Permitted to be reused from Jpn. J. Appl. Phys. [13]. (C) Japan Society Applied Physics).

To increase understanding of the background to achieving the current AlGaN-based LEDs with high performance, optimizing AIN growth recipes during the preparation before production is discussed in the following. The MOCVD performed in the experiment used a tray of multiple wafers. The effect of the miscut angles was investigated for two years, where we expected that AlN grown on $0.2^{\circ}$ - and $0.3^{\circ}$-miscut sapphire would have a stepflow surface and that AlN on $1.0^{\circ}$-miscut sapphire would have dense macrosteps. The comparison was based on XRC measurements and EL output measurements in reliability tests. During the optimization procedure, the AlN growth recipe was modified on the basis of this routine analysis. The appearance of macrosteps on AlN on sapphire with miscut angles less than $0.3^{\circ}$ was overlooked simply because there was no increase in the number of device faults. Before starting the production, AlN surfaces on sapphire with various miscut angles were observed by AFM for confirmation. It was indeed surprising to see that the entire AlN surface exhibited was rough. Including the case of AlN grown on $1.0^{\circ}$-miscut sapphire, which was expected to have dense macrosteps, the number of LED wafers subjected to the reliability tests was about 1000 and the number of LED dies was about 10,000. Statistically, the rough surface on AlN cannot be a reason for device faults. During this preparation before the mass production of DUV-LEDs, different reasons for device faults were revealed and measures were taken. Due to this background, the results using sapphire with a miscut of less than $0.3^{\circ}$ reported in this article might include those of devices both smooth and rough surfaces. 

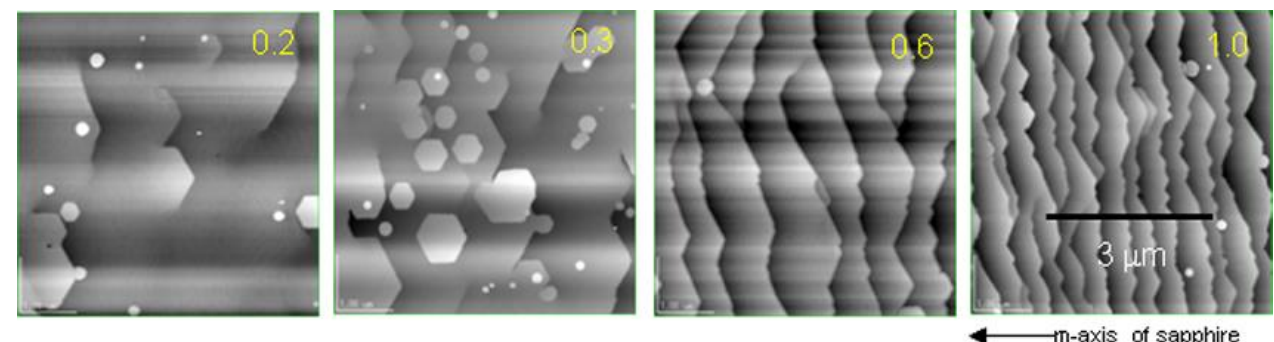

(a)

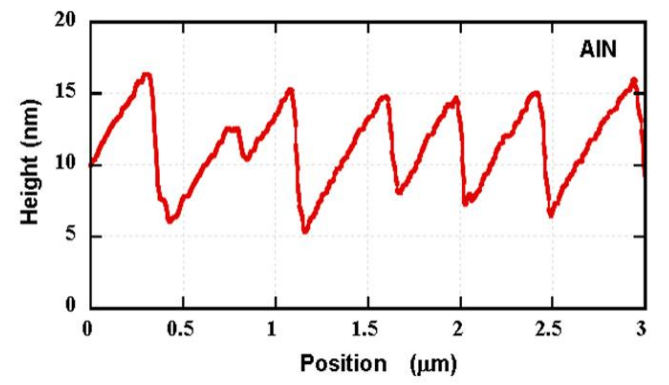

(b)

Figure 5. (a) AFM images $\left(6 \times 6 \mu \mathrm{m}^{2}\right)$ of AlN templates on sapphire substrates with various miscut angles after optimizing the AlN growth recipe before starting mass-production. Macrosteps unexpectedly appeared for the low-miscut sapphire samples. The LEDs on these AlN templates showed no adverse effects due to the macrosteps in the reliability tests, indicating the robustness of the QWs grown on macrosteps. (b) Height profile of AlN on $1.0^{\circ}$-miscut sapphire along the line in the image. Ra value of AlN template is 2.26. ((a) images for the miscut angle of $0.3^{\circ}$ and $1.0^{\circ}$ and (b) are permitted to be reused from Jpn. J. Appl. Phys. [13]. (C) Japan Society Applied Physics).

The use of high miscut sapphire has the additional advantages of lowering the growth temperature and enabling the use of a thinner AlN layer to obtain AlN with a TDD on the order of $10^{8} / \mathrm{cm}^{2}$. When the growth temperature was set to lower than $1300{ }^{\circ} \mathrm{C}[13,38]$, the growth rate of AlN was reduced to around $1 \mu \mathrm{m} / \mathrm{h}$. However, the use of $1.0^{\circ}$-miscut sapphire enables the growth of a 2-3- $\mu$ m-thick AlN layer with a TDD on $5 \times 10^{8} / \mathrm{cm}^{2}$ on sapphire. The growth time for the AlN layer did not exceed about $3 \mathrm{~h}$, meaning that it is practically applicable to mass-produce DUV-LEDs. Despite the decreased growth rate, the lower growth temperature solved the problem of a short lifetime for the consumables in the growth chamber. The lifetime of the consumables is in a trade-off relationship to the growth rate and the lower growth temperature increases the interval between growth chamber maintenance. From an industrial viewpoint, increasing the yield of the dies in a wafer as well as the yield of wafers due to reduced run-to-run fluctuation is also important and the reduction of heat transfer due to infrared radiation contributes to reduce the run-to-run fluctuation. To conclude this Section, the use of high-miscut sapphire is considered to be effective in the current situation.

\section{Reflective p- and n-Electrodes}

\subsection{Transparent p-Cladding Layer and Reflective p-Contact}

InGaN-based LEDs normally comprise a p-GaN cladding layer with transparency to the wavelength about above $365 \mathrm{~nm}$. Ag-based solder has reflectivity in $\lambda>365 \mathrm{~nm}$ and many silver-colored metals are well known to have significant reflectivity in NUV $(\lambda>300 \mathrm{~nm})$. The use of indium tin oxide (InSnO: ITO) enables a conductive transparent $(\lambda>365 \mathrm{~nm}) \mathrm{p}$-contact. By integrating such a cladding layer and p-contact, when the metallized sapphire side of InGaN dies is bonded to the packaging, the pair of transparent $\mathrm{p}$-contacts and the Ag-based solder realizes a high light extraction efficiency 
(LEE). In addition, when the reflective p-contact is flip-chip bonded to the mount, the utilization of EL reflected from the $\mathrm{p}$-contact is possible.

Meanwhile, for DUV-LEDs, neither a transparent conductive p-cladding layer nor a low resistive p-contact on p-AlGaN cladding layer can be practically used. The conventional p-contact metal of $\mathrm{Ni}$ does not reflect DUV at $\lambda<280 \mathrm{~nm}$. Although as-deposited Al reflects DUV, Al is unsuitable for formation of low-resistivity contacts on $\mathrm{p}-\mathrm{GaN}$, owing to its small work function. This explains why many reports of DUV-LEDs with a p-reflective electrode show a high $V_{f}$. $V_{f}$ of $7 \mathrm{~V}$ [23] using a short-period superlattice (SPSL) has been reported. In addition, $\mathrm{Ni} / \mathrm{Au}$ and $\mathrm{Ni} / \mathrm{Al}$ contacts with an increased forward voltage of 2-4 V [114] when $\mathrm{p}-\mathrm{GaN}$ contact layer is replaced by p-AlGaN. Furthermore, a Ni/Al contact with $\mathrm{V}_{\mathrm{f}}$ over $15 \mathrm{~V}$ [42], a Rh electrode with $\mathrm{V}_{\mathrm{f}}=16 \mathrm{~V}$ [21], or a Ni/Mg electrode with an embedded photonic crystal $(\mathrm{PhC})$ structure without recording $\mathrm{V}_{\mathrm{f}}$ [43] were reported. None of the reports $[21,24,42,43,114]$ mentioned the lifetime. We also attempted to form a contact on a p-AlGaN layer, resulting in LEDs with a very short lifetime. To suppress the increase in $V_{f}$ and reduction in the lifetime, a meshed $\mathrm{p}-\mathrm{GaN}$ contact layer was used [40], which increased $V_{\mathrm{f}}$ to 6-7 V. Although the reduction in the lifetime was suppressed, the problem was not sufficiently solved, as shown in Figure 6. The reasons for the short lifetime have not yet been clarified and the suggestion of the local heat generation due to insufficient contact is possibly among the reasons. Since LEDs must have a lifetime of over 10,000 h to be superior to the UV bulbs, a p-GaN contact layer is currently thought to be necessary. Simple approaches of the reflective p-contact did not lead to a practical solution. Attempts to solve the problem by inserting a thin InGaN layer [115-117], incorporating quantum dots [118], or fabricating nanorods [119] are ongoing. However, major manufacturers currently incorporate a p-GaN contact layer. Due to the insufficient conductivity of p-AlGaN [120] of about $10^{2} / \Omega \mathrm{cm}$, the p-AlGaN contact resistivity of about $10^{-2} \Omega \mathrm{cm}^{2}$ [121], and the absence of a practical reflective p-contact in DUV region, the waste EL towards the p-side is not expected to be utilized in near future.

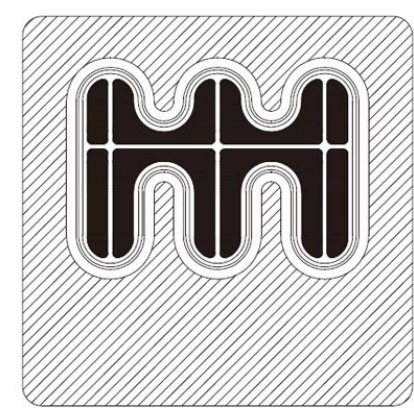

(a)

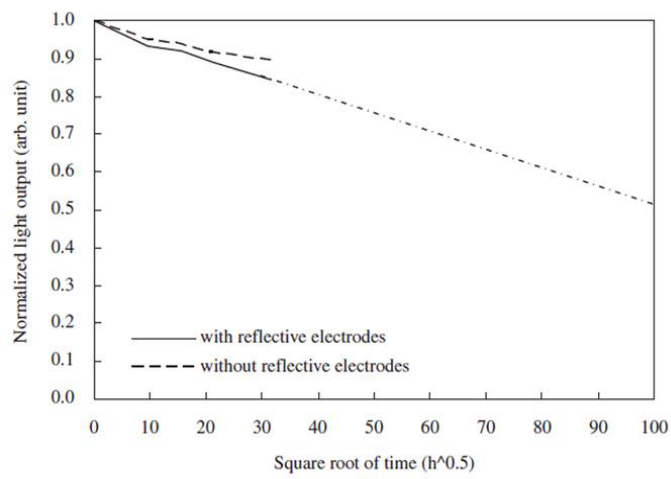

(b)

Figure 6. (a) Meshed p-GaN contact pattern is shown by narrow white lines besides the black area, which preserves the reflective area (black). Beside the hatched zone, a closed curve zone (white) indicates the Al-based n-contact area with annealing treatment. (b) Result of the reliability test. The reduction in the lifetime was suppressed. The reliability test was carried out at as low as $20 \mathrm{~mA}$ to avoid the further reduction in the lifetime. $((\mathbf{a}, \mathbf{b})$ are permitted to be reused from Jpn. J. Appl. Phys. [40]. (C) Japan Society Applied Physics).

\subsection{Interdigital Reflective n-Contact}

The part of the EL traveling backwards to the device layers, which is reflected from the sapphire-air boundary, is absorbed in the p-GaN layer of DUV-LEDs, resulting in the waste of the EL. To reduce the waste EL on this mechanism, an n-reflective contact was investigated [40]. The sheet resistance of the n-contact on $\mathrm{Al}_{\mathrm{x}} \mathrm{Ga}_{1-\mathrm{x}} \mathrm{N}(\mathrm{x}>50 \%)$ was recorded to be around $10^{-4} \Omega \mathrm{cm}^{2}$ [122] using vanadium. The carrier concentration of the $\mathrm{n}-\mathrm{AlGaN}$ layer and the electron mobility were 
reported [123]. However, because the $\mathrm{n}-\mathrm{AlGaN}$ cladding layer and the n-contact are highly resistive compared with those of $\mathrm{n}-\mathrm{GaN}$, an interdigital n-electrode is usually applied $[13,26]$ to supply the current uniformly to the junction area, as shown in Figure 6. An increased length of the mesa sidewall enables a narrow $n$-contact area adjacent the junction area. The reflectivity in DUV at n-contact is lost by the annealing treatment to lower the contact resistivity. This annealing process is currently unavoidable to minimize the increase in $V_{\mathrm{f}}$. The part of the n-electrode adjacent to the junction area was annealed to form a low-resistivity contact, and then the $\mathrm{Al}$ was post-deposited on the rest of the contact area of $\mathrm{n}-\mathrm{AlGaN}$. As a result, an EQE was improved by 1.2-fold [40] with a small increase in $\mathrm{V}_{\mathrm{f}}$. Since the area of an n-reflective electrode has a trade-off relationship with the junction area, the practical use of n-reflective electrodes should be limited, because the current density in the junction area must be reduced by increasing the junction area to obtain a longer lifetime. Therefore, a n-reflective contact is not applied to our device layers.

\section{Factors Inhibited Light Extraction at the Interfaces with Different Refractive Indices}

Currently, the use of $\mathrm{p}$ - or n-reflective electrodes does not practically improve DUV-LEDs. Since the waste EL comes mainly from the absorption in the p-GaN layer, the reduction of the reflection loss at the boundary between sapphire and air is recognized as a priority task to extract more light from the bare dies. Based on the concept without increasing both $\mathrm{V}_{\mathrm{f}}$ and WPE, the control of the surfaces of sapphire or the AlN substrate opposite the device layer has been studied $[18,37,62]$ to increase LEE. AlN substrates are thinned to reduce DUV absorption at AlN. By roughening the thin AIN surface, an enhancement of LEE greater than 1.5-fold was achieved [18,62]. A motheye (photonic crystal: PhC) structure [124] was fabricated on sapphire substrate [37]. As a result, the EL output obtained by wafer-based measurement without isolating into dies was improved 1.5-fold, as shown in Figure 7.

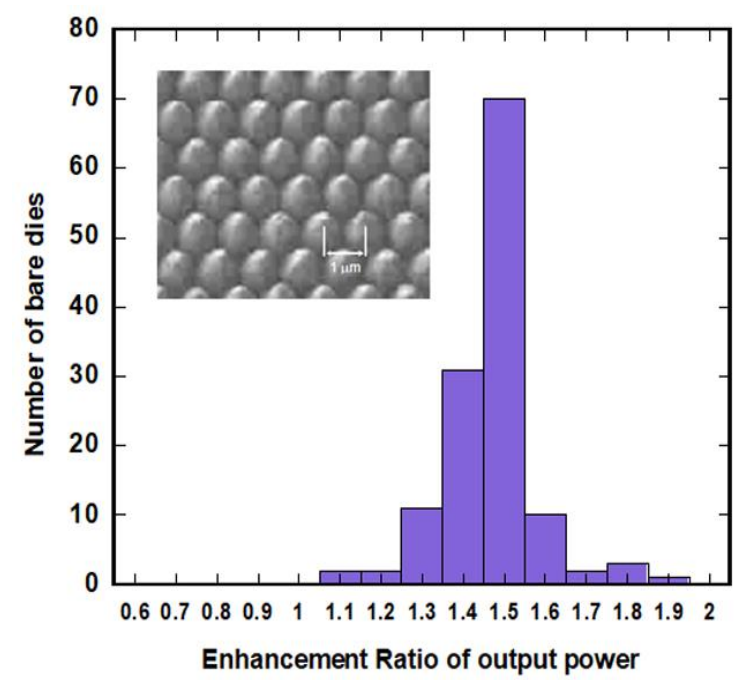

Figure 7. Relative increases in EL output power measured by wafer prober without dicing the LED wafers shown as a histogram. The inset is a scanning micro scope (SEM) image of the moth-eye (PhC) structure fabricated on sapphire. After isolating into dies from the LED wafer with maintaining the sapphire substrate thickness at $430 \mu \mathrm{m}$, the improvement in the EL output was reduced to about $5 \%$ because the contribution of sapphire sidewalls in increasing LEE. (Graph is permitted to be reproduced from Appl. Phys. Express [37]. @ Japan Society Applied Physics).

Since the Mohs hardness of sapphire is 9 (Vickers hardness of 2300), thinning the sapphire before scribing the LED wafer is generally used to mass-produce commoditized wire-bonded InGaN-based devices with a p-transparent electrode. For the flip-chip mounted devices, heat dissipation is mainly via the p-contact and the thickness of sapphire layer is not a serious disadvantage. However, the thinning process is normally applied before scribing sapphire due to its hardness. The use of thick sapphire 
became possible using the stealth-dicing-technique invented by Hamamatsu. When LED wafers were isolated without thinning 430- $\mu \mathrm{m}$-thick sapphire, the improvement ratio of LEE resulting from using the moth-eye structure was decreased to around $5 \%$ because of the contribution of thick sapphire sidewalls for increasing in LEE. The moth-eye $(\mathrm{PhC})$ structure is still substantially effective because there is no increase in $V_{f}$, no reduction of the lifetime, and disadvantages except for the cost. Currently, thick sapphire is considered to be a useful material with a refractive index of 1.8 , between those of air and AlN (refractive index 2.1) [125]. Because of the improvement of only 5\% by motheye (PhC) structure on the sapphire surface opposite to the device layers in the case of using thick sapphire, the encapsulation was focused on as a priority [14,15].

Due to the difference in the refractive indices between sapphire and AlN, the reflection between the sapphire and AIN layer cannot be negligible. The use of $\mu \mathrm{m}$-size PSS [39] was studied, keeping in mind the future application of PhC instead of the $\mu \mathrm{m}$-sized PPS. The use of PSS was expected to reduce this reflection loss and improve the quality of AlN crystal. For AlN to coalesce on PSS, the preferable miscut angle of sapphire was determined to be lower than $0.3^{\circ}$ [126]. The use of PSS conflicted with the use high miscut sapphire. Consequently, the present device layers of DUV-LEDs were grown on planar sapphire with $1.0^{\circ}$ miscut.

\section{Present Simple Bare Die}

As described in Section 4, high miscut sapphire is useful for obtaining moderate crystallinity with a TDD between $10^{8}$ and $10^{9} / \mathrm{cm}^{2}$. As described in Section 5, reflective p-contact is considered to reduce the lifetime. In addition, due to increase in $\mathrm{V}_{\mathrm{f}}$ due to the low electrical properties of the $\mathrm{p}$-AlGaN cladding layer and reflective p-contact, WPEs cannot be expected to increase remarkably. In addition, reflective n-contact was not applied because the enlarging junction area in the limited die size is considered to be practical. Thick sapphire is considered to be effective technique to increase WPE and the moth-eye (PhC) structure is not currently used because it only increases the LEE by $5 \%$ in the case of using thick sapphire.

Consequently, planar thick sapphire with a high miscut angle of $1.0^{\circ}$ has been used to obtain moderate crystallinity as well as to simplify the fabrication of DUV-LEDs. Figure 8a illustrates the DUV-LED structure presented in the sections from 10 to 14 and Figure $8 \mathrm{~b}$ shows the electrode pattern and the dimensions of the die.

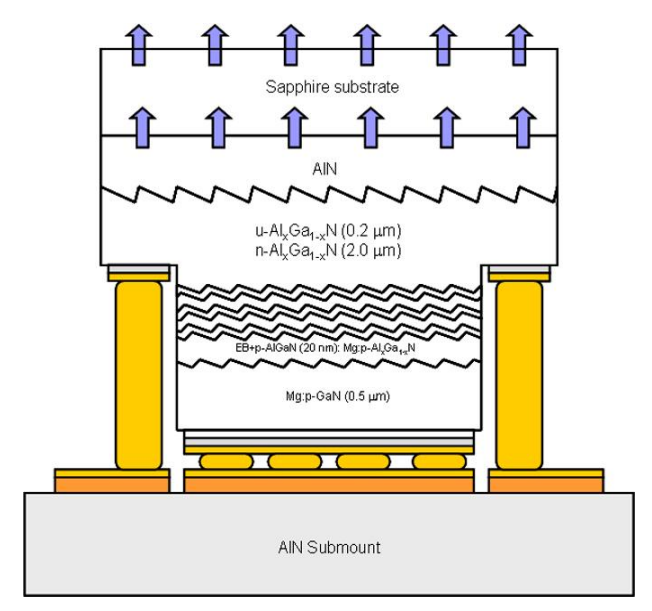

(a)

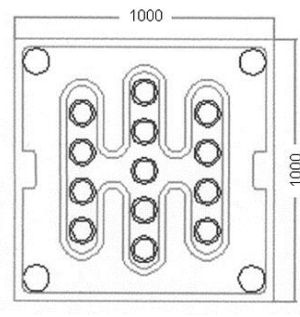

(b)

Figure 8. (a) Block diagram of DUV-LED die on thick sapphire with $1.0^{\circ}$ miscut and submount. (b) Electrode pattern of interdigital n-contact on $1000 \times 1000 \mu \mathrm{m}^{2}$ die. The Au stud bumps used to flip-chip the die onto the submount are indicated by circles in the junction area. Thirteen and four bumps are located in the junction area and n-contact area, respectively. $((\mathbf{a}, \mathbf{b})$ are permitted to be reused from Jpn. J. Appl. Phys. [13]. (C) Japan Society Applied Physics). 


\section{Packaging for DUV-LEDs}

Packaging loss is often neglected in scientific research; however, even a simple mount such as a TO-5 stem causes packaging loss. This is mainly because of the low reflectivity of metals in the DUV region. AlN ceramic heatsink contains impurities because AlN ceramic is fabricated by sintering, reducing the transparency to DUV. Accordingly, the measurement of EQEs is unavoidably accompanied by packaging loss. Even though a high EQE is obtained, transverse or backward EL emission to the normal vector of the sapphire light extraction plane opposite to the device layers is not useful. It would be preferable to collect this EL closer to the light extraction side of devices. Practically, an $\mathrm{Al}$ reflector around the die is effective to reduce the waste of EL. An Al coating on the surface of the submount will also reduce the waste.

From the industrial viewpoint, packaging loss is a serious problem for DUV-LEDs. Today's regular DUV-LEDs are mounted on ceramic container-type package, which enables applying established mass-production machines and attaching the quartz window, because it is well known that most polymers are decomposed by DUV light. In addition, heat dissipation is important to enable the injection of a larger current. High EQE does not necessarily lead to highly useful devices, and a high absolute output power or irradiation intensity is often required. Robust InGaN LEDs are often driven at a high current density over $50 \mathrm{~A} / \mathrm{cm}^{2}\left(500-700 \mathrm{~mA}\right.$ per $1 \times 1 \mathrm{~mm}^{2}$ die).

Currently, WPEs of DUV-LEDs are less than $10 \%$ and the injected energy to DUV-LEDs is mainly converted into heat. Since AlGaN, as well as InGaN, material is robust, to increase usable EL outputs, heat dissipation of the packaging is the key to injecting a larger current. Sintered AlN ceramic has a thermal conductivity coefficient of more than $170 \mathrm{Wm}^{-1} \mathrm{~K}^{-1}$ and is durable against DUV light. One of the current problems in AlN packaging originates from the reflection between the quartz window and the atmosphere in DUV region. The loss at the quartz window is $8 \%$ or greater. In addition, the coefficients of thermal expansion differ for AlN and quartz window. To attach the packaged DUV-LEDs on the patterned circuit board (PCB), solder reflow process is desired to be used, which needs to increase the furnace temperature up to $260^{\circ} \mathrm{C}$. Despite the problems of reflow temperature and the reflection loss at the window, many manufacturers currently use precise ceramic packaging with a quartz window. To attach the quartz window, AlN multilayer sintering technique was applied to make the height of inner walls greater than the die thickness. However, the inner walls cause serious packaging loss of the EL flux oriented to transverse to the axis of light extraction direction, which is not expected to be highly reflected from the inner walls. The total packaging loss is estimated to be $40 \%$, resulting EL output of $45 \mathrm{~mW}$ in the case of packaging when the output of the corresponding bare die is more than $70 \mathrm{~mW}$ [127]. To reduce the loss of the quartz window and low reflection from the inner walls, encapsulation using a fluoro-polymer is considered to be useful $[14,15]$.

\section{EL Output Measurement for DUV-LEDs}

Normally, packaging loss is difficult to completely separate from EQE measurements. We attempted to attach an $\mathrm{Al}$ reflector on simple planar AlN submount and confirmed that the measured EQEs increased by $5-8 \%$ when using a four-inch integrating sphere with the sample mounted on the outer spherical surface. The following measurements do not incorporate reflector or a reflective coating on the AlN mount. Thus, the determined EL outputs are not considered to be overestimated. The container-type AlN packaging with inner walls were not used to determine the die performances.

When measuring DUV light, the absorption by the atmosphere, the sensitivity of sensors in the UV region, and the accuracy of the standard light source must be carefully considered. The international standard light source is based on the black body radiation and tungsten filament bulb (2855.6 K), which is defined by commission internationale de l'éclairage (CIE). The standard light source guarantees an accuracy of 5.6-11.6\% for DUV in Japan, which might not differ significantly from the standard of other countries. The UV emission of a tungsten filament is weak and it is not user friendly. There are standard light sources with intense UV emission employing xenon or deuterium lamps calibrated by Japan Calibration Service System (JCSS) for regular use. The lifetime of the standard light 
source for regular use is only $100 \mathrm{~h}$ despite the need for stabilization time before its use. To perform a daily check between the checks using the standard light, a stable light source such as an NUV- or DUV-LED is helpful.

Our standard light source has been a Hamamatsu L7810-02 (xenon lamp) since the beginning of our research on AlGaN-based LEDs. Standard light sources without the guaranteed intensity of DUV region are on the market. UV measurement has pitfalls because of its similarity to that of visible light. Regarding absorption of atmosphere, $\mathrm{O}_{2}$ with a nonsymmetrical magnetic moment absorbs light with a wavelength of around $210 \mathrm{~nm}$. DUV light with wavelength between $100 \mathrm{~nm}$ and $230 \mathrm{~nm}$ creates ozone with absorption from 350 to $250 \mathrm{~nm}$. In addition, $\mathrm{OH}$ molecules have absorption structures $\left(\mathrm{A}_{2} \Sigma^{+}-\mathrm{X}_{2} \Sigma^{+}\right.$transition) at around $245-315 \mathrm{~nm}$ [128], meaning the care of humidity is preferable. Therefore, the absorption along the optical path between the LED and detector must be considered. Our integrating sphere is a 4-inch sphere having a short optical path and with the inner sphere surface coated by the fluoro-polymer (polymerized tetra-fluoro-ethylene (PTFE)). This is designed to be used for DUV; however, the decomposition of PTFE by the DUV near $200 \mathrm{~nm}$ should be cared about. Based on our experience, when it is located in a clean room, it will give comparable accuracy to that of the standard light source at wavelengths of $\lambda>250 \mathrm{~nm}$. Nitrogen gas with a symmetrical molecular structure is useful for purging the gas inside the sphere to eliminate UV absorption.

\section{DUV-LED Layers with Uneven QWs Grown on Macrosteps}

Figure 9 shows the result of AlN grown on 430- $\mu$ m-thick sapphire with miscut angles of $0.2^{\circ}$, $0.3^{\circ}$, and $1.0^{\circ}$ relative to the m-axis of (0001) sapphire. This experiment was performed in parallel with optimization of the growth recipe for AlN for two years. The growth temperature was set to be between 1220 and $1280{ }^{\circ} \mathrm{C}$ during the growth of AlN layer. Based on the result shown in Figure 9, the miscut angle of the sapphire substrate was set to $1.0^{\circ}$ to fabricate LED wafers. The crystallinity of $2-\mu \mathrm{m}$-thick AlN in the case of $1.0^{\circ}$-miscut sapphire was stable [13]. The FWHMs of the $\omega$-scans of (0002) and (10-10) XRCs were about 150 and $650 \mathrm{arcsec}$, respectively. The total of the FWHMs of the $\omega$-scans of (0002) and (10-10) XRCs was determined to be quite stable at about $800 \pm 15.5$ arcsec because of the trade-off relationship between tilt (0002) and twist (10-10) [13]. A TDD of $5 \times 10^{8} / \mathrm{cm}^{2}$ was estimated for our AlN in the case of using $1.0^{\circ}$-miscut sapphire. The AlN on the sapphire exhibited dense macrosteps after optimizing the AlN growth recipe, as shown in Figure 5. In the case of the $1.0^{\circ}$-miscut sapphire, the terrace width was about $300 \mathrm{~nm}$ and the step height was often greater than $10 \mathrm{~nm}$, which is greater than the well thickness of 2-3 nm or the quantum barrier thickness of 6-7 nm. To determine the roughness of the quantum well, $\mathrm{n}-\mathrm{Al}_{\mathrm{x}} \mathrm{Ga}_{1-\mathrm{x}} \mathrm{N}$ cladding layers were grown on AlN templates and atomic force microscope (AFM) images were taken for cladding layers with $x=0.67$ and 0.61 , which were prepared for 265 and $285 \mathrm{~nm}$ LEDs, respectively. After characterizing the $n-\mathrm{Al}_{\mathrm{x}} \mathrm{Ga}_{1-\mathrm{x}} \mathrm{N}$, 3QW and $20 \mathrm{~nm}$-thick-electron blocking (EB) layers were regrown on the $\mathrm{n}$-AlGaN templates. Figure 10 shows AFM images of the n-AlGaN templates and EB surfaces. Al-rich EB surfaces were used to determine the roughness of the final surface of the MQW because the decomposition of the Ga-rich MQW during the cooling process of MOCVD must be prevented. The large step edges on the AlN surface were divided into multiple macrosteps on the n-AlGaN and EB surfaces for both the $\mathrm{x}=0.67(265 \mathrm{~nm})$ and $0.61(285 \mathrm{~nm})$ cases. This is considered as a footprint of mass transport during the $\mathrm{AlGaN}$ growth. In addition, the step edges lost their sharpness at the AlN surfaces which can be seen in Figure 5, suggesting that the macrosteps collapsed during the AlGaN growth. However, the height of the macrosteps on $\mathrm{n}-\mathrm{AlGaN}$ and EB surfaces often exceeded $10 \mathrm{~nm}$, which is greater than the quantum well and quantum barrier thicknesses. Since uneven QWs are thought to be unsuitable to grow QWs on it, the authors' group previously attempted to make a flat template [109]. EM groups also reported $\mathrm{n}$-AlGaN with a flat surface with an RMS of less than $0.3 \mathrm{~nm}[71,113]$. We unexpectedly observed that the uneven QWs function well. Then, samples with EB surfaces were used to regrow p-GaN layers, where the thickness of each $\mathrm{p}-\mathrm{GaN}$ layer was about $0.5 \mu \mathrm{m}$. A laser microscopic image of the $\mathrm{p}-\mathrm{GaN}$ surface is shown in Figure 11. Due to compressive strain given by the EB surface, the p-GaN growth 
became three-dimensional mode before forming a smoother $\mathrm{p}-\mathrm{GaN}$ surface. A high miscut angle of the sapphire prevented the formation of stepflow surfaces of $\mathrm{p}-\mathrm{GaN}$. Despite the surface having an arithmetic average roughness ( $\mathrm{Ra}$ ) of 5.86 for $6 \times 6 \mu \mathrm{m}^{2}$ area, this thick $\mathrm{p}-\mathrm{GaN}$ layer is considered to be indispensable for obtaining a lifetime of over $10,000 \mathrm{~h}$. Similar to the manufacturers of DUV-LEDs using sapphire, manufacturers of DUV-LEDs on AlN bulk substrates also incorporate thick p-GaN layers $[30,62]$.

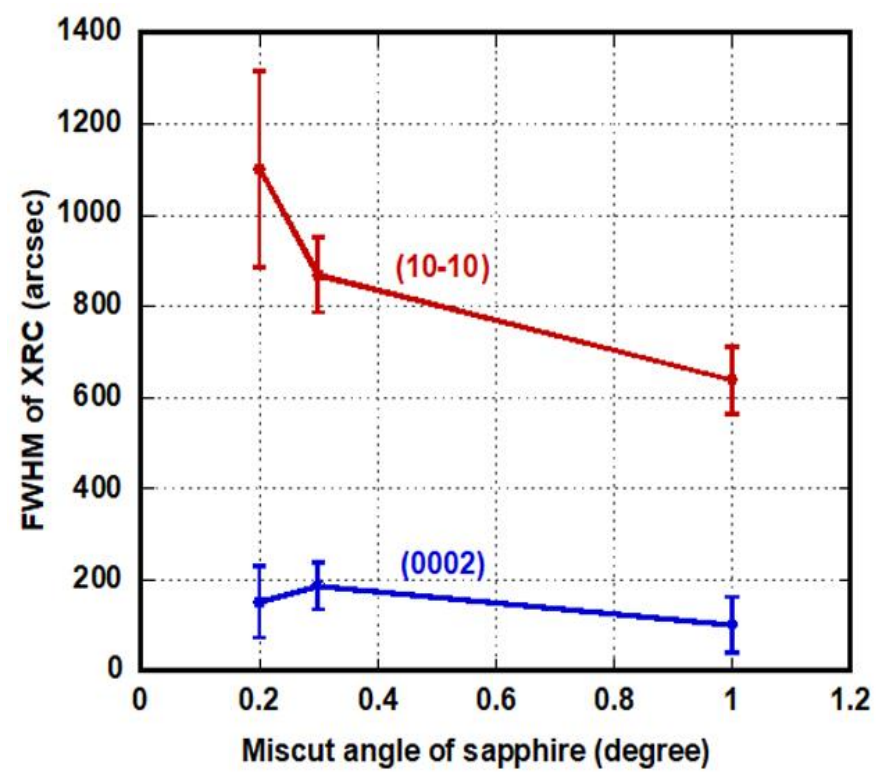

Figure 9. Results of AlN template grown on sapphires with miscut angles of $0.2^{\circ}, 0.3^{\circ}$, and $1.0^{\circ}$. The numbers of samples with $0.2^{\circ}-, 0.3^{\circ}$-, and $1.0^{\circ}$-miscut sapphire were 25,20 , and 43 , respectively. The FWHMs of $\omega$-scans of the (0002) and (10-10) XRCs were $101 \pm \sigma 61$ and $638 \pm \sigma 74$ arcsec, respectively, for the sapphire with a miscut angle of $1.0^{\circ}$. The thickness of AN was slightly greater than $2 \mu \mathrm{m}$ and the growth rate was set to about $1 \mu \mathrm{m} / \mathrm{h}$. (Permitted to be reproduced from Jpn. J. Appl. Phys. [13]. (C) Japan Society Applied Physics).

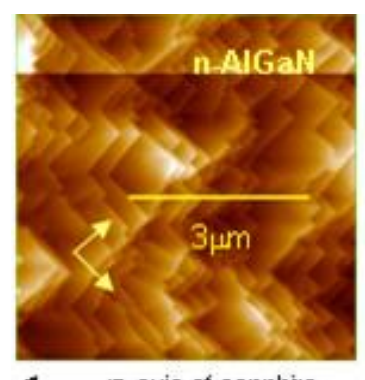

4 m-axis of sapphire

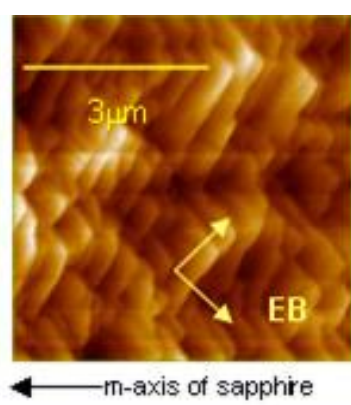

(a)

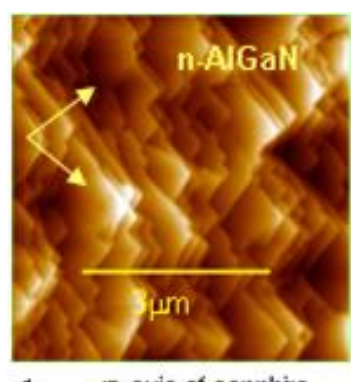

m-axis of sapphire

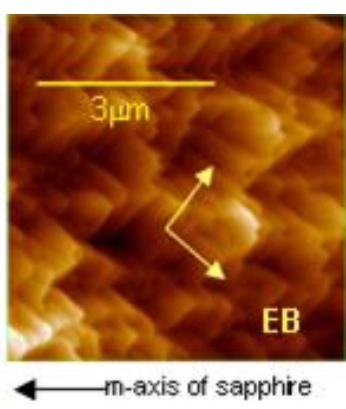

(b)

Figure 10. AFM images of $n-\mathrm{Al}_{\mathrm{x}} \mathrm{Ga}_{1-\mathrm{x}} \mathrm{N}$ surface and EB surface used to determine the external forms of uneven QWs for: (a) x = 0.61 (265 nm LEDs); and (b) x = 0.67 (285 nm LEDs). The Ra values for the height plots along the yellow lines are 1.38 and 1.12 for the surfaces of $n-\mathrm{Al}_{0.61} \mathrm{Ga}_{0.39} \mathrm{~N}$ and $\mathrm{EB}$ layers in (a) and 1.42 and 1.43 in (b), respectively. The arrows in the AFM images are considered to be the $\mathrm{m}$-axis of the AlGaN. These AFM images are distorted because of the non-contact-mode measurement. $((\mathbf{a}, \mathbf{b})$ are permitted to be reused from Jpn. J. Appl. Phys. [13]. ( J Japan Society Applied Physics). 


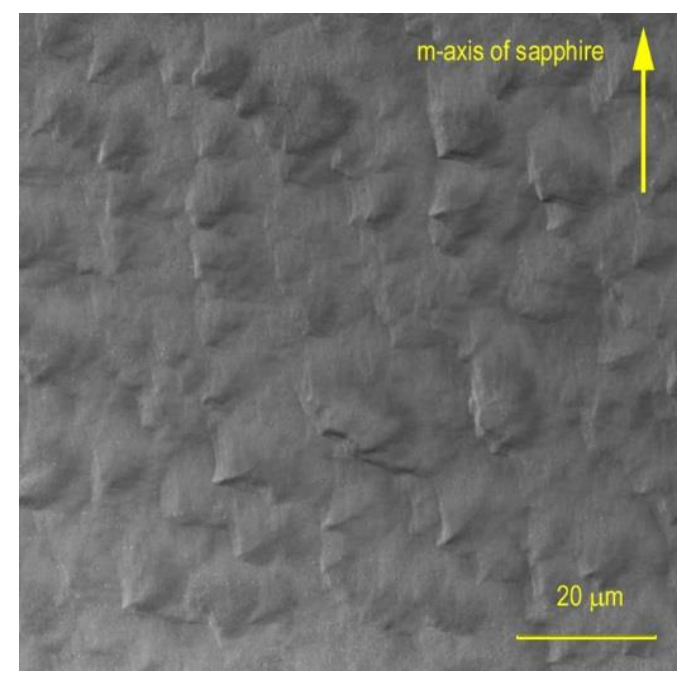

Figure 11. Laser microscopic image of $\mathrm{p}-\mathrm{GaN}$ surface. The thickness of the p-GaN layer is $0.5 \mu \mathrm{m}$. The roughness $(\mathrm{Ra})$ is 5.86 . The $\mathrm{p}-\mathrm{GaN}$ surface was obtained by erasing the hexagonal pyramids via three-dimensional growth. (Permitted to be reproduced from Jpn. J. Appl. Phys. [13]. @ Japan Society Applied Physics).

\section{EQEs, WPEs and IQEs of AlGaN-Based Bare Dies with Uneven QWs}

Due to the thickness of the p-GaN layer, approximately half of the generated EL propagating to the p-side is immediately absorbed in the p-GaN. To avoid the waste of EL propagating to the n-cladding layer, $430-\mu \mathrm{m}$-thick sapphire was used without thinning. Four samples of DUV-LEDs were fabricated: 266 and $271 \mathrm{~nm}$ LEDs were grown on a $265 \mathrm{~nm}$ template group $(\mathrm{x}=0.67)$ and 283 and $297 \mathrm{~nm}$ LEDs were fabricated on a $285 \mathrm{~nm}$ template group $(\mathrm{x}=0.61)$. Dies were placed on an AlN submount $\left(3 \times 3 \mathrm{~mm}^{2}\right)$ with a thickness of 0.015 inch $(0.381 \mathrm{~mm})$ and then mounted on TO- 5 headers. The specific heat dissipation for TO-5 is limited to $120 \mathrm{~mW}$. Figure 12 shows the EL intensity as a function of the injected current (I-L characteristics) with the I-V characteristics shown in the inset. Figure 13 shows corresponding WPEs. The peak EQEs were obtained at $40 \mathrm{~mA}$. EQEs of $3.5 \%$ at $266 \mathrm{~nm}, 3.8 \%$ at $271 \mathrm{~nm}, 6.1 \%$ at $283 \mathrm{~nm}$, and $6.0 \%$ at $298 \mathrm{~nm}$ were achieved. The load of $40 \mathrm{~mA}$ is slightly larger than the specific heat dissipation of TO- 5 headers because $\mathrm{V}_{\mathrm{f}}$ is between 5 and $6 \mathrm{~V}$. The peak WPEs were $3.0 \%$ at $266 \mathrm{~nm}, 3.4 \%$ at $271 \mathrm{~nm}, 5.4 \%$ at $283 \mathrm{~nm}$, and $5.5 \%$ at $298 \mathrm{~nm}$ at DC currents of 40,20,10, and $5 \mathrm{~mA}$, respectively. At $100 \mathrm{~mA}$, the WPEs were reduced to 2.7, 3.1, 4.4, and $4.3 \%$ at $266,271,283$, and $298 \mathrm{~nm}$, respectively.

The IQEs of these samples could not be precisely determined. However, rough estimates of IQEs are possible using I-L curves [129]. The LEE of the structure with $\mathrm{p}-\mathrm{GaN}$ has been estimated by several groups to be $8-9 \%$ using ray tracing $[24,41]$. We also estimated on LEE of $8 \%$ for our DUV-LEDs. Assuming a fixed LEE and eliminating the effects of the shunt and parallel resistances of the LEDs, the relationship between the EL intensity and injected current density in the junction area enables the current injection efficiency (CIE) and IQE to be calculated. However, this method is based on a fixed LEE and the effect from such as a chipping of sapphire sidewalls was neglected. Therefore, the IQEs were conservatively estimated assuming a LEE of $10 \%$ and an improbable CIE of $100 \%$. Thus, conservative IQEs of 35, 39, 61, and 60\% were estimated for the 266, 271, 283, and $298 \mathrm{~nm}$ LEDs, respectively. The high IQEs of these samples are recognized. Because the TDD was on the order of $10^{8} / \mathrm{cm}^{2}$, these IQEs led us to consider the carrier localization effect. From our many CIE estimations based on I-L characteristics, CIE at around $265 \mathrm{~nm}$ is considered to be about $20-30 \%$ smaller compared with that at around $285 \mathrm{~nm}$. The CIE of $70-80 \%$ at around $265 \mathrm{~nm}$ is considered to be moderately conservative, and the expected IQE ranges are shown in Table 2. The samples correspond to the solid red circles in Figure 1. 


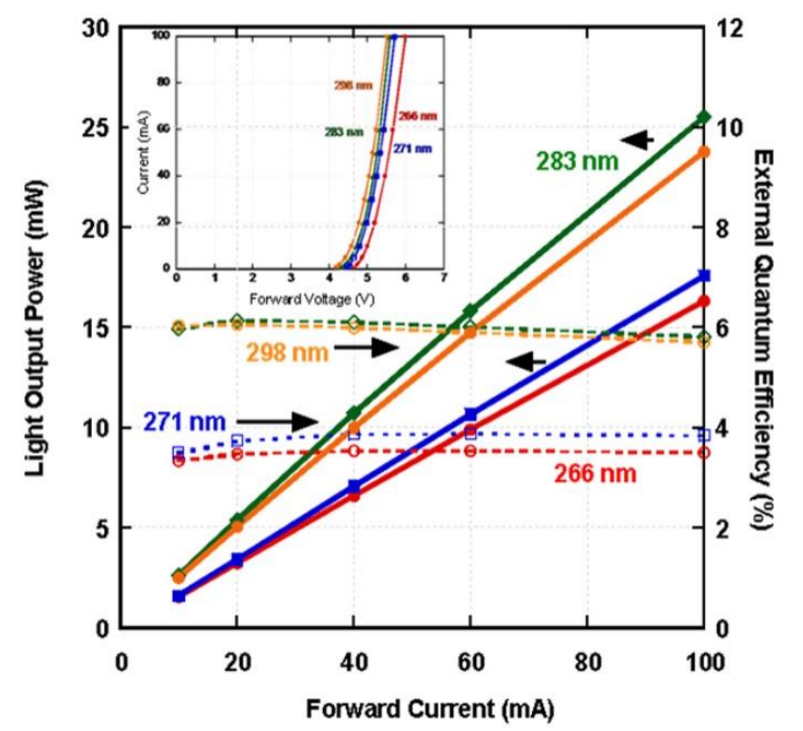

Figure 12. EQEs and I-V characteristics of AlGaN-based DUV-LEDs. The four samples correspond to the solid red circles in Figure 1. (Permitted to be reused from Jpn. J. Appl. Phys. [13]. (C Japan Society Applied Physics).

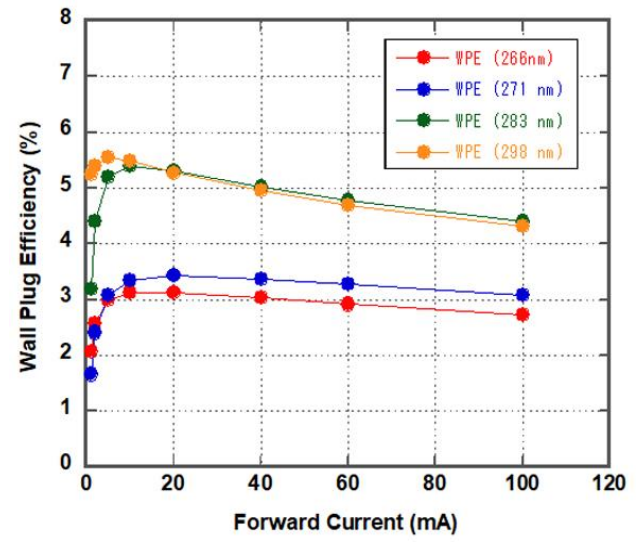

(a)

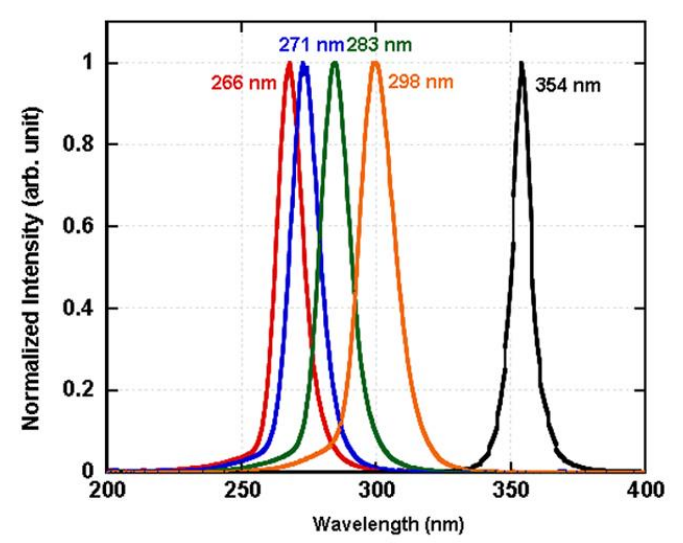

(b)

Figure 13. (a) WPEs of AlGaN-based DUV-LED bare dies; and (b) their EL spectra, with an LED with a GaN well $(354 \mathrm{~nm}$ ) having a spectral width of $75 \mathrm{meV}$ shown for a reference without ternary disordering. The samples are the same as those in Figure 12 and the EL spectral widths are greater than $200 \mathrm{meV}$ for the AlGaN wells, also suggesting potential fluctuation at the QWs. ((a) is calculated WPE from Figure 12. (b) is permitted to be reused from [13]. (C) Japan Society Applied Physics).

Table 2. IQEs estimated from the fixed LEE and CIE. To show the expected range of the IQE at $40 \mathrm{~mA}$, the values in the lower rows are considered to be the more probable IQEs. The values with CIE/LEE of $100 / 10$ are conservative estimates for 283 and $298 \mathrm{~nm}$ LEDs. The values with CIE/LEE of 80/10 are the possible conservative estimates for the $266 \mathrm{~nm}$ LEDs, assuming that the CIE at $265 \mathrm{~nm}$ is $20 \%$ less than those of 283-298 nm LEDs. (Calculated from the data at $40 \mathrm{~mA}$ in Figure 12.).

\begin{tabular}{ccccc}
\hline CIE/LEE (\%) & 266 nm & 271 $\mathbf{~ m ~}$ & 283 $\mathbf{~ n m}$ & $\mathbf{2 9 8} \mathbf{~ n m}$ \\
\hline $100 / 10$ & $(35)$ & $(38)$ & 61 & 60 \\
$90 / 10$ & $(39)$ & 42 & 68 & 67 \\
$80 / 10$ & 43 & 48 & 76 & 75 \\
$70 / 10$ & 50 & 54 & & \\
\hline
\end{tabular}




\section{Reliable DUV-LEDs with Uneven QWs}

QWs or MQWs are generally controlled to be flat. Accordingly, a tremendous number of reliability tests have been performed to determine that uneven QWs are robust and reliable using about 1000 wafers and 10,000 dies. In the following reliability test, a $5 \times 5 \mathrm{~mm}^{2}$ AlN submount and a patterned circuit board (PCB-MT) $\left(16 \times 16 \mathrm{~mm}^{2}\right)$ with an isolation layer of diamond-like carbon (DLC) on an oxidized aluminum layer on $1.5-\mathrm{mm}$ thick duralumin were prepared. Dies were mounted on the AlN submount, which was then mounted on the PCB-MT. Figure 14 shows the results of the reliability tests for 265 and $285 \mathrm{~nm}$ LED dies at an injected current of $350 \mathrm{~mA}$. The current density in the junction area was more than $100 \mathrm{~A} / \mathrm{cm}^{2}$. Despite this heavy load, no serious reduction in their lifetimes was observed. By improving the bottleneck of heat dissipation due to the multiple bumps between the submount and the dies, the commercially available products show a lifetime much greater than $10,000 \mathrm{~h}$.

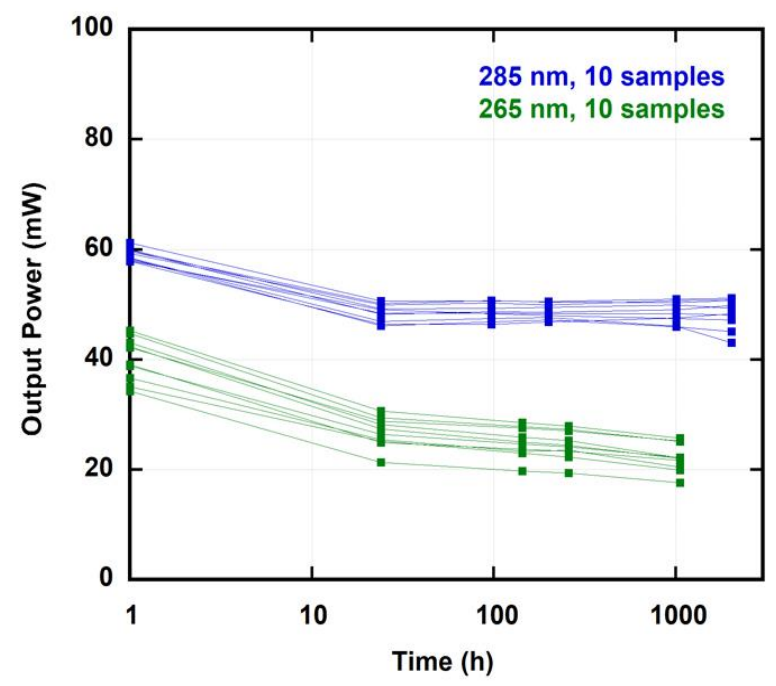

Figure 14. Reliability tests for 265 and $285 \mathrm{~nm}$ LEDs. The tests were carried out at $350 \mathrm{~mA}$ ( $>100 \mathrm{~mA} / \mathrm{cm}^{2}$ in the junction area), which is 3.5 times higher than $100 \mathrm{~mA}$ in our previous report [13], demonstrating the robustness of the AlGaN-based uneven QWs.

\section{Characteristic Behaviors of Uneven QWs}

\subsection{Redshift of EL Spectra with Increasing Number of Macrosteps}

The FWHMs of the XRCs for the (0002) and (10-10) $\omega$-scans in Figure 9 indicate a TDD higher than $10^{8} / \mathrm{cm}^{2}$, which led us to consider the carrier localization effect for both 265 and $285 \mathrm{~nm}$ LEDs. The carrier localization effect for AlGaN QWs has been reported $[86,130]$. In addition, it is well known that reducing the TDD increases the IQE in QWs by reducing the number of nonradiative recombination centers (NRCs) [77]. Therefore, the following experiments are considered to be affected by both the lowered TDD and the enhanced carrier localization resulting from the use of high-miscut sapphire.

The redshift of the EL spectra as a function of miscut angle was observed in the case of high-miscut sapphire as shown in Figure 15. To minimize the run-to-run fluctuation, simultaneous growth using multiple wafer trays was performed several times and no exceptions to the results in Figure 15 were observed. In Figure 15a, the results for two pairs of the simultaneously grown 260 and $280 \mathrm{~nm}$ LEDs are shown, and in Figure 15b the results for three pairs of simultaneously grown 265, 285, and $300 \mathrm{~nm}$ LEDs are shown. The reasons for the spectral redshift in the case of higher-miscut sapphire are next hypothesized. The enhancement of compositional and thickness modulation by macrosteps may be among the reasons for the increased potential modulation. The potential nonuniformity will increase the IQE in MQWs due to the localized carriers. Note existence of a spectral shoulder at around 
$295 \mathrm{~nm}$ in two of the spectra in Figure 15b shown by a gray dashed line. The wavelength of the shoulder is common for the 285 and $300 \mathrm{~nm}$ LEDs and suggests the existence of quasi-stable AlN in AlGaN. This quasi-stable AlN is suggested to be related to the high-EQE region between 280 and $300 \mathrm{~nm}$ in Figure 1. The peak EQE of $295 \mathrm{~nm}$ can also be seen in the EQE mapping of Figure 1. Thus, enhanced compositional nonuniformity should occur around this wavelength, and the carrier localization induced by the compositional nonuniformity is considered to boost the IQE. Note that this does not imply that the compositional fluctuation on a flat terrace should be neglected, because somewhat lower EQEs were reported for flat QWs for the DUV-LEDs with p-GaN [19,21]. In addition, the enhanced mass transport near the macrosteps may cause thickness modulation because it is reasonable to consider the different growth rate between the surfaces of the step-edge and (0001) surface of AlGaN. The growth rate on the step-edge should be larger. Therefore, the enhanced carrier localization may be due to a complicated combination of mechanisms.

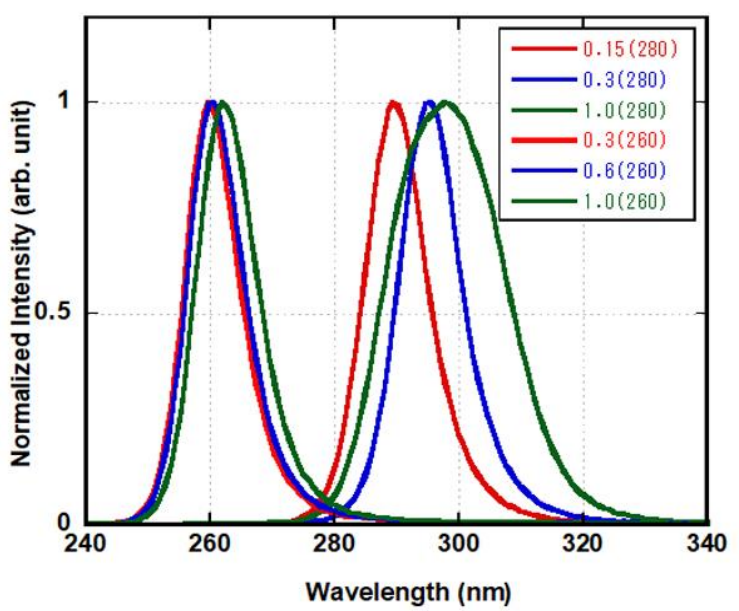

(a)

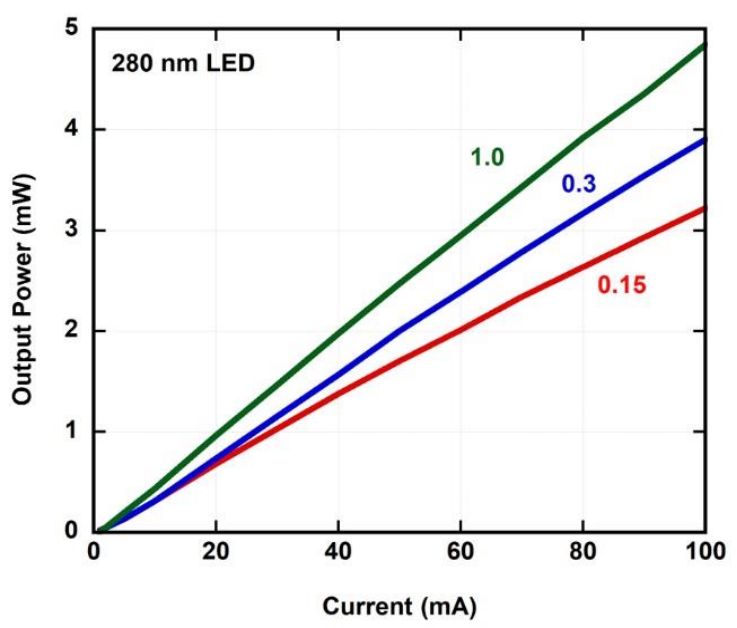

(c)

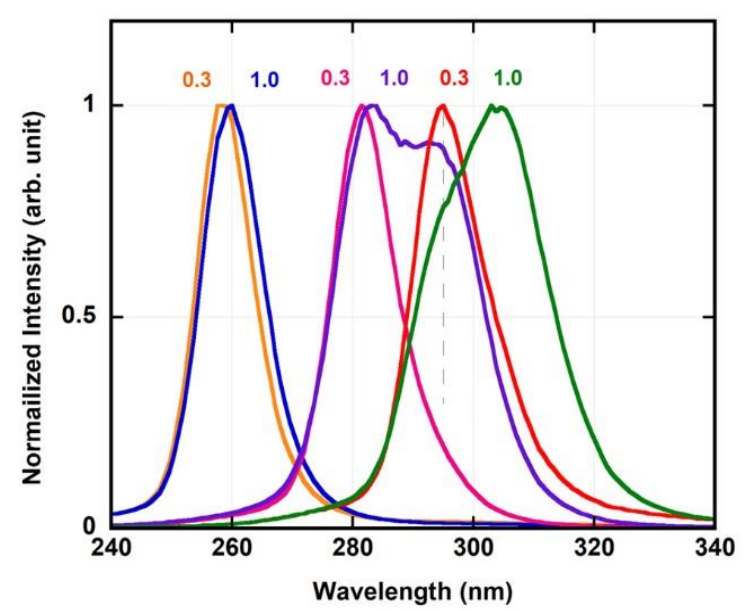

(b)

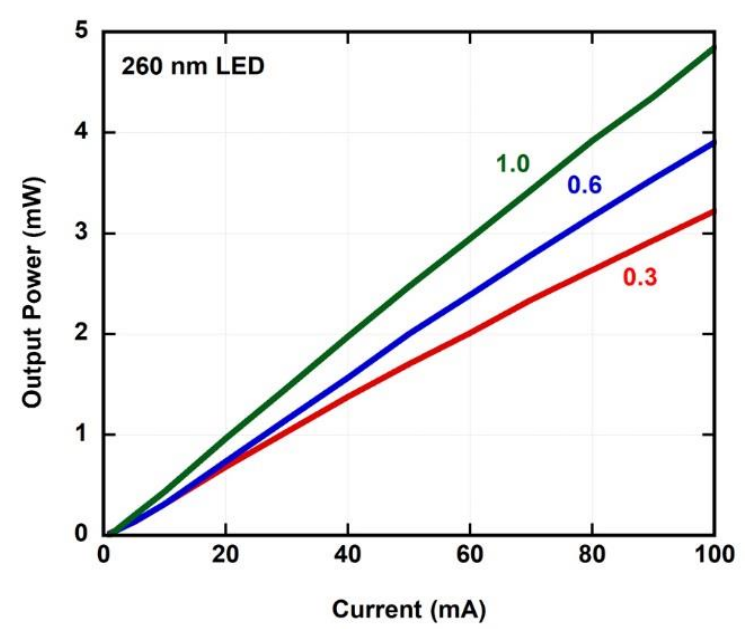

(d)

Figure 15. (a,b) Redshift of EL spectra observed in case of using high-miscut sapphire. The spectra in (a) were controlled to have single peaks. (c,d) I-L characteristics of 260 and $280 \mathrm{~nm}$ LEDs for different miscut angles of sapphire, respectively. Graph (b) includes spectra with a shoulder to show the possible existence of quasi-stable AlN in AlGaN. The indices above the spectra or I-L characteristics in $(\mathbf{b}, \mathbf{d})$ denote the miscut angles of sapphire. Both $(\mathbf{c}, \mathbf{d})$ show that the EL output increases with increasing miscut angle of sapphire for the samples in (a). ((b) is permiited to reuse from [13] and (a,c,d) are permitted to reuse from Proc. SPIE 9926, 99260C (2016) [131].). 
In Figure 15a, a smaller spectral redshift and less spectral broadening with the increase in the miscut angle of sapphire can be seen for the $260 \mathrm{~nm}$ LEDs. To explain the somewhat lower EQEs for the $260 \mathrm{~nm}$ LEDs, it is reasonable to consider the lower CIEs due to insufficient electrical properties of electron blocking layer compared with those for $280 \mathrm{~nm}$ LEDs. In addition, the lower mass transport and the lack of quasi-stable AIN for the QWs of the $260 \mathrm{~nm}$ LEDs may be a reason for the smaller enhancement of carrier localization than that for the $280 \mathrm{~nm}$ LEDs. Thus, the lower IQEs for the $260 \mathrm{~nm}$ LEDs than those for the $280 \mathrm{~nm}$ LEDs can be understood. Accordingly, the lower EQE for the $260 \mathrm{~nm}$ must be due to both lower CIE and lower IQE.

It is reasonable that the broadening of the EL spectra is accompanied by a redshift when the overlapped spectral structures are considered. Accordingly, Figure 15 shows indirect evidence of carrier localization due to enhanced potential modulation adjacent to the macrosteps for both the 265 and $285 \mathrm{~nm}$ LEDs. There might be a difference between the 265 and $285 \mathrm{~nm}$ LEDs due to the presence/absence of quasi-stable AlN. Although there are detailed differences between 265 and $285 \mathrm{~nm}$ LEDs, the EQEs can be increased by the use of high-miscut sapphire, which can be attributed to the increased IQEs achieved by reducing the TDD. To provide further indirect evidence of increased IQEs due to enhanced potential modulation adjacent to the macrosteps, the analysis of DUV-LEDs with a similar TDD is desirable to isolate the effect of the potential nonuniformity from that of the TDD.

\subsection{EL Spectral Broadening with Increase in EL Output for the Same TDD}

Higher output power is obtained for broader EL spectra when the miscut angle of sapphire is varied. However, the above results cannot eliminate the effect of the increase in EQE caused by the reduction of the TDD, because the TDD is improved by the use of high-miscut sapphire. Although the spectral redshift and the increase in EL output were accompanied with an increase in the number of macrosteps, increase in the EL output for the broader EL spectra was not clear for the sapphire with the same miscut angle. The authors expect that a simple mapping of the EL spectral width to the EL output power for the same TDD will reveal the positive relationship between the EL output and spectral width. Due to the large run-to-run fluctuation for AlGaN and AlN growth, it was difficult to ensure the relationship between EL output and spectral width during the improvement of the growth recipes. Countermeasures to the run-to-run fluctuation problem were intensively investigated before mass production. Next, a positive relationship between the EL output and spectral width was observed when the miscut angle was fixed to $1.0^{\circ}$ in the routine growth of DUV-LEDs. Although it is difficult to separate the effects of potential fluctuation on the terrace and potential modulation adjacent to the macrosteps, the effect of carrier localization related to EL broadening in our experiments can be extracted.

LED wafers grown on $\mathrm{n}-\mathrm{AlGaN}$ templates with similar XRCs were collected to minimize the effect of the TDD. In this procedure, the balance between the FWHMs of the-scans of the (0001) and (1010) XRCs was considered in the analysis of $285 \mathrm{~nm}$ LED wafers, where the detailed procedure is described in Ref. [13]. The EL outputs determined by a wafer prober were collected for both 265 and $285 \mathrm{~nm}$ LED wafers. The n-AlGaN templates have a TDD of about $5 \times 10^{8} / \mathrm{cm}^{2}$. The wafer prober measurement at the wafer center was strongly correlated with the EL output after fabricating LED dies at the wafer center, where the XRC measurements were performed. The linearity of the EL output measurements obtained with the wafer prober and the integrating sphere after isolation into dies was confirmed to be within $20 \%$. To eliminate the wavelength dependence shown in Figure 1, the LED wafers were sorted into groups according to the wavelength of the peak EL output. Then, positive correlations between the spectral width and EL output power were observed for 265 and $285 \mathrm{~nm}$ LEDs, as shown in Figure 16a, b. These figures provide further evidence that the higher EL output is related to enhanced carrier localization due to increased potential nonuniformity. Using templates with similar TDDs and surfaces with macrosteps grown on $1.0^{\circ}$-miscut sapphire, an increase in the EL output for a broader spectral width was also observed. The results in Figure 16 cannot definitively conclude the enhancement of carrier localization by potential modulation adjacent to the macrosteps. 
However, this is considered to be in agreement with the hypothesis of the enhancement of EL output by carrier localization. Detailed microscopic analyses are in progress. Cathode-luminescence (CL) spectral peaks besides the macrosteps were confirmed to be redshifted, increasing the plausibility of the hypothesis that enhanced carrier localization is related to macrosteps.
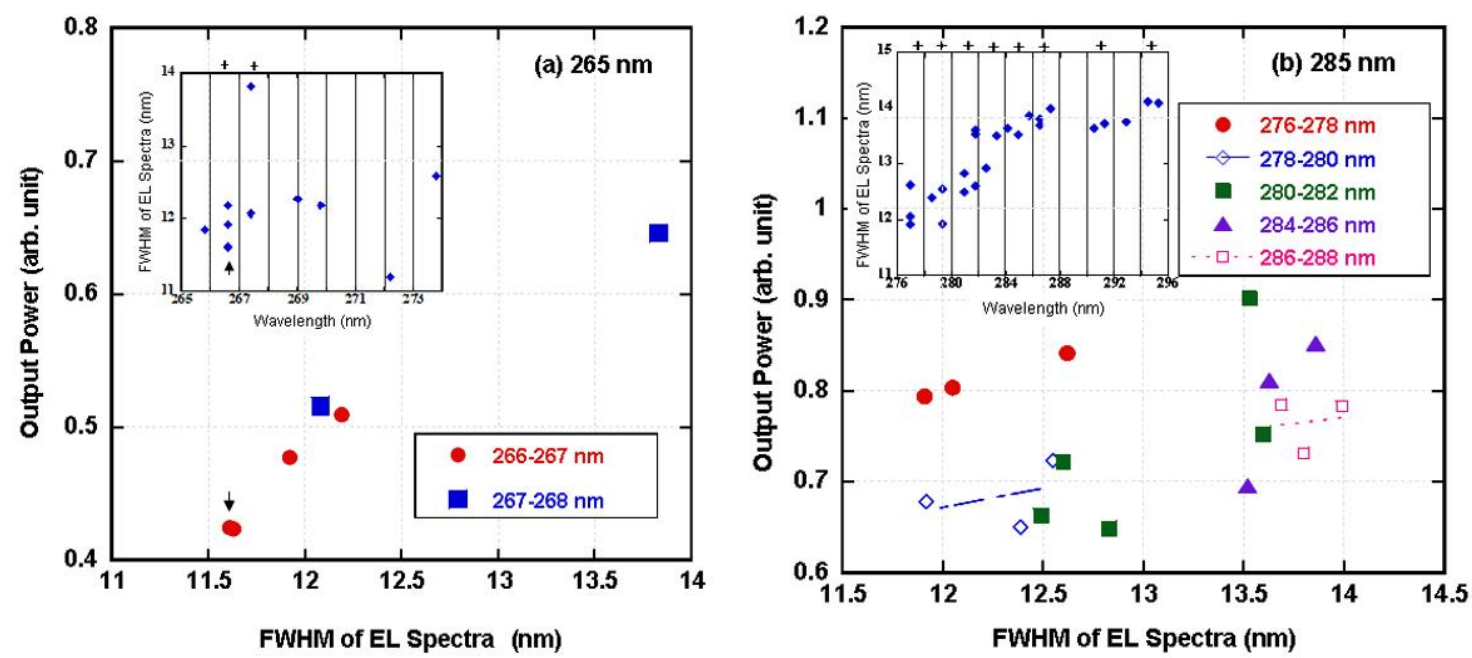

Figure 16. $(\mathbf{a}, \mathbf{b})$ Increased EL output in accordance with EL spectral broadening. The sapphire miscut angle was set to $1.0^{\circ}$. The TDD values and the density of macrosteps of the templates are considered to be within a narrow range. The numbers of (a) $265 \mathrm{~nm}$ and (b) $285 \mathrm{~nm}$ LED wafers were 11 and 23, respectively. For (b) $285 \mathrm{~nm}$ LEDs, the dependence of EL output on FWHM of EL spectra is vague to see the relationship between EL output and spectral width when the EL output and spectral width were simply mapped. When the samples wafers were grouped by the wavelength of peak EL, a positive correlation between the EL output and spectral width was seen for all groups of $285 \mathrm{~nm}$ LEDs, as indicated by the " + " symbols above the insets. The arrows indicate two overlapping data in graph (a). The dotted line in (b) shows the weak positive correlation. (Figures are permitted to be reused from Jpn. J. Appl. Phys. [13] @ Japan Society Applied Physics).

\section{IQEs of AlGaN-Based Uneven QWs}

Many of the reported IQEs are determined using the ratio of photoluminescence (PL) intensity at room temperature (RT) to that at a low temperature (LT). The model for this measurement is simplified by considering one type of NRC. This model requires other assumptions. The electron $\left(n_{e}\right)$ and hole $\left(n_{h}\right)$ densities are assumed equal to the representative carrier density $(n)$ at QWs, and the recombination terms are separated according to the order of the carrier density $n: A n, B n^{2}$, and $C n^{3}$.

Here, $A$ is a nonradiative recombination coefficient related to the Shockley-Read-Hall (SRH) NRCs, which is related to the probability for the carriers to be captured by NRCs. Thus, $A$ strongly varies with temperature (T). $B$ is an emission coefficient linear to the Einstein $A$ coefficient based on the concept of the possibility of a radiative combination of electron-hole pairs at the QWs. Thus, $B$ is multiplied by the square of the carrier density in the QWs assuming free carriers. $C$ implies nonradiative Auger recombination concerning three carriers, and the $n^{3}$ term is multiplied. In the case of a device with a high carrier density such as LDs, the $C$-term is necessary. For LEDs, $C$ is often approximated to be negligible [77]. At the LT limit, SRH-NRCs are assumed to be occupied and frozen out; thus, all the injected carriers are considered to be converted to EL. When SRH-NRCs are frozen at $\mathrm{LT}$, the quantum yield $(\varphi)$ can be near $100 \%$ by freezing $A(T \rightarrow 0)$ to zero. The quantum yield $(\varphi)$ with a function of $T$ is defined as

$$
\varphi(T)=\frac{B n}{A(T)+B n}
$$


When the number of carriers (n) injected into QWs is sufficiently large to be $A \gg B n, \varphi(T)$ is overestimated at $T \gg 0$. Therefore, nonsaturated excitation is necessary to obtain appropriate IQE values in this measurement. The junction temperature $\left(T_{j}\right)$ is considered to be increased by a high-energy excitation. The saturated excitation makes it difficult to assume $T_{j}$ with approximation to the temperature of the sample holder.

In the discussion on IQEs, the reported data $[24,25,41,61,90,113,132-137]$ are collected and shown as solid symbols $(\bullet, \square, \mathbf{\square}, \bullet, \square, \bullet, \bullet)$ for the measurements under the nonsaturated conditions. Figure 17 shows the IQEs as a function of wavelength. The hollow symbols in Figure 17 indicate the calculated or measured IQEs reported without mentioning nonsaturated excitation. There is another method of enabling the separation of IQE and CIE [129] using I-L characteristics. However, it is based on the given LEE and considered to be a rough estimate. Thus, our IQEs ( $\Delta$ and $\boldsymbol{\nabla}$ ) were calculated to be conservative estimates from I-L characteristics by assuming a fixed LEE of $10 \%$ and high CIEs ranging from $70 \%$ to $100 \%$, as shown in Table 2. Our estimates of the IQEs of the uneven MQWs are compared with solid symbols $(\bullet, \square, \mathbf{\square}, \bullet, \mathbf{\bullet}, \bullet, \bullet)$ of the MQWs, which are considered to be flat. In the 265-290 nm range, the uneven QWs show equal or higher values than the reported ones measured with flat MQWs on AlN grown on a sapphire substrate $(\square, \bullet)$ and on a bulk AlN substrate (๑). In the $255-265 \mathrm{~nm}$ region, data for AlGaN wells grown on the bulk AlN spread over a wide range of IQEs from 15 to $80 \%$ (๑ and $\bullet$ ). In the 230-245 nm region, IQEs on the macrosteps were reported for the samples grown on the bulk AlN substrates $(\bullet)$ as well as on the sapphire substrates $(\square)$. Also, flat MQW without Si doping grown on a sapphire substrate is indicated by ( $\square)$.

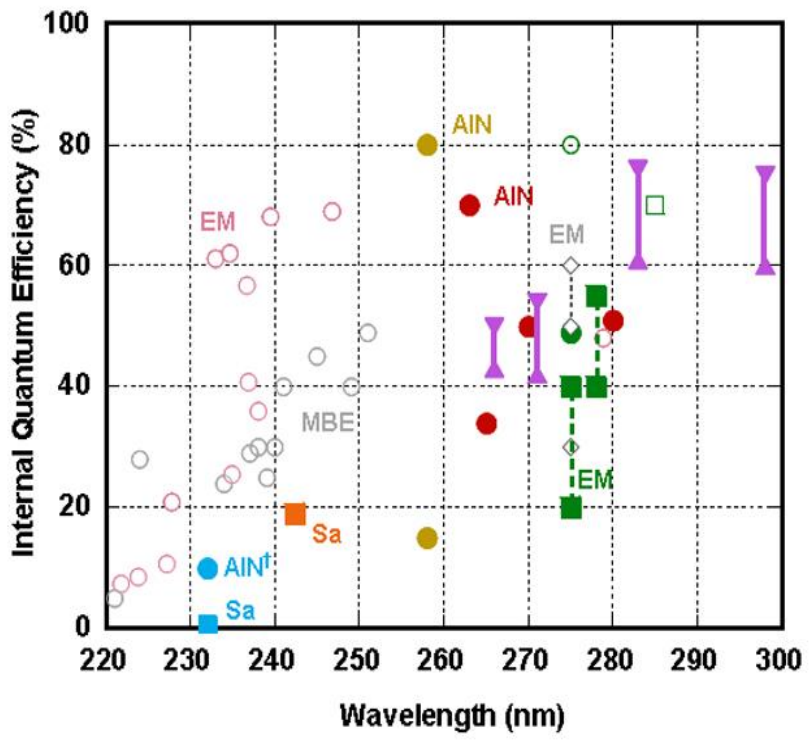

Figure 17. The reported IQE dependence on the wavelength is collected and mapped. This graph includes the calculations and IQEs under unclear excitation conditions, as shown by hollow symbols.

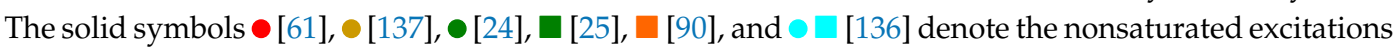
for flat MQWs. Our estimated ranges for the uneven QWs are shown by $(\boldsymbol{\Delta}$ and $\boldsymbol{\nabla})$. AlN ${ }^{\dagger}$ indicates the uneven MQW grown on bulk AIN with a miscut of $3.0^{\circ}$ shown by $\bullet$, and $\square$ refers to the flat MQW grown on sapphire [136]. EM denotes the enhanced migration method used for AlN growth on sapphires. MBE indicates samples prepared by a molecular beam epitaxy method.

Figure 18 shows a map of the relationship between TDD and IQEs, eliminating the IQE data measured under unclear excitation conditions. Our IQE ranges are shown by violet triangles. The upper solid triangles $(\boldsymbol{\Lambda})$ are conservative estimations for our DUV-LEDs using LEE/CIE of $10 \% / 100 \%$. The IQEs for undoped and Si doped MQWs are shown by $\square$ and $\bullet$, respectively [90]. In Figure 18, IQEs determined considering excitation conditions are added ( 
references of flat MQWs. For the AlGaN QWs, the aluminum vacancy $\left(\mathrm{V}_{\mathrm{Al}}\right)$ is demonstrated to act as NRC. Si-doped MQWs show higher IQEs than that of the undoped MQW because of decreasing $\mathrm{V}_{\mathrm{Al}}$ [90]. The results of MQWs grown on the bulk AlN substrates are plotted at a TDD of $10^{6} / \mathrm{cm}^{2}$ because of unknown TDDs at the MQWs. The IQEs for MQWs on the bulk AlN substrates range from 10 to $80 \%(\bullet, \bullet, \bullet)$. The EL wavelength for the samples $(\bullet, \bullet)$ are located between 255 and $265 \mathrm{~nm}$ and the AlN content in AlGaN QWs are higher than those of our samples. Thus, $\mathrm{V}_{\mathrm{Al}}$ is considered be among the reasons for the IQE difference [60,137]. The IQE estimates of the uneven MQWs $(\boldsymbol{\Delta}$ and $\boldsymbol{\nabla})$ are above the IQE-TDD trend curve (blue) similarly to Si-doped MQWs (๑) compared with undoped MQW ( $\square)$, suggesting the boosted IQEs due to macrosteps. It is possible that the macrosteps cause the mass transport of Ga and GaN components in AlGaN [138] during the growth of the MQWs. It led us to consider the possibility that the number of $\mathrm{V}_{\mathrm{Al}}$ has been reduced by the mass transport adjacent to macrosteps in addition to the enhanced carrier localization due to potential modulation. In Figure 17, the IQE of MQWs on the macrosteps on an AlN bulk substrate with a miscut of $3.0^{\circ}(\odot)$ and that of a flat MQW grown on a sapphire substrate $(\square)$ are added. The increased IQE (॰) on a $3.0^{\circ}$-miscut AIN substrate also supports the boosted IQE for AlGaN MQWs on the macrosteps.

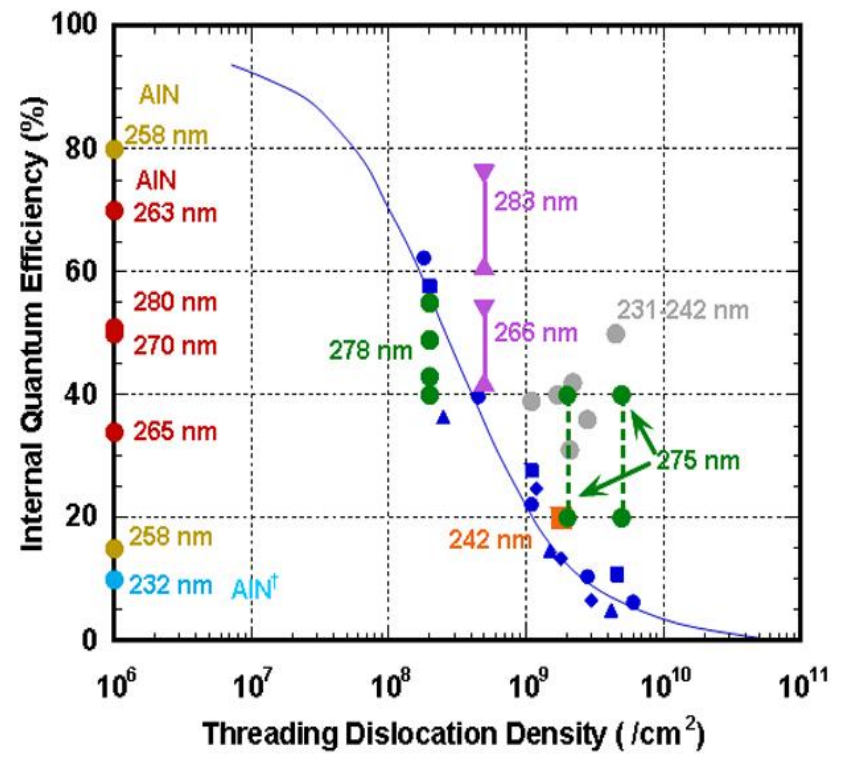

Figure 18. The reported IQEs as a function of TDD are mapped. The data for the flat AlGaN MQWs determined under nonsaturated conditions are plotted with $\bullet$ [61], • [137], @ [24,25], घ [90] and [136] solid symbols. The solid blue plots are the measured IQEs considering excitation conditions for the flat MQWs with wavelengths $230 \mathrm{~nm}(\bullet), 250 \mathrm{~nm}(\boldsymbol{\square}), 300 \mathrm{~nm}(\bullet)$, and $350 \mathrm{~nm}(\boldsymbol{\Delta})$, and the blue curve show the relationship between TDD and IQE [77]. AlN indicates the use of the bulk AlN substrate, which is gathered at TDD of $10^{6} / \mathrm{cm}^{2}$. The violet symbols denote the uneven MQWs on macrosteps for our samples from Table 2. The gray circles $(\bullet)$ indicate the IQE boosted by Si-doped MQW [90] and the rest is considered to be data for undoped MQWs (colored symbols). $\mathrm{AlN}^{\dagger}$ indicates the uneven QWs.

\section{Prospects for EQE and WPE with Advanced Packaging}

For the devices with a $\mathrm{p}-\mathrm{GaN}$ contact layer and no reflective p-contact, improving the LEE from the sapphire side is important. Using thick sapphire without thinning, the increase in the surface area of sapphire can increase the extraction of EL propagating to the sapphire. However, the shape of the sapphire opposite the device layers of dies is a rectangular parallelepiped, resulting in a significant amount of EL being wasted. EL from the MQWs is reflected at the sapphire-air boundary. Thus, a part of the EL returns to the device layers and is absorbed in the p-GaN or not reflected from the n-electrode area. The shape effect has not been sufficiently utilized to increase LEE. A material with 
a spherical shape is considered to be effective for improving our rectangular parallelepiped dies. However, the shaping of the thick sapphire is difficult due to its hardness. In addition, the difference between the refractive indices of sapphire (1.8) and air is large. The use of a material with a refractive index between those of air and sapphire is also desired.

To overcome these problems, resin encapsulation using silicone [54], fluorine [13,14], and unknown type of resins $[17,19]$ has been reported. Our intensive studies on the use the fluoropolymer to encapsulate DUV-LED dies clarified a molecular structure with robustness against DUV $[13,14,139]$. The LEE and WPE were improved 1.5-fold in the case of hemispherical encapsulation using the fluoropolymer. In addition to the encapsulation, the minor practical improvements of: (i) using an $\mathrm{Al}$ reflector around the die; (ii) forming an $\mathrm{Al}$ coating on the submount; and (iii) forming an $\mathrm{Al}$ coating on the insulation film on the mesa sidewall are thought to be effective for improving the net WPE without reducing the lifetime due to the use of $\mathrm{p}-\mathrm{AlGaN}$ and a reflective p-contact. In addition, (iv) the formation of a moth-eye (PhC) structure on the sapphire surface can also increase the net EQE and WPE without reducing the LED lifetime. Although the flexible shaping of sapphire is difficult, (v) chamfering the sapphire of the die is considered possible and may be an effective measure in addition to encapsulation using a fluoropolymer. Based on our limited experimental attempts, an additional 1.2-fold improvement is conservatively expected by adapting (i)-(v). In Figure 13, the 1.5-fold WPEs at $100 \mathrm{~mA}$ are estimated to be $4.1 \%, 4.6 \%, 6.6 \%$, and $6.5 \%$ at $266,271,283$, and $298 \mathrm{~nm}$, respectively, from the WPEs corresponding to red solid circles in Figure 1. In addition, when additional improvement of 1.2 -fold is assumed, WPEs of $4.9 \%, 5.5 \%, 7.9 \%$ and $7.8 \%$ at $100 \mathrm{~mA}$ are expected. A single bare die in the market fabricated by our group demonstrated about $80 \mathrm{~mW}$ at $285 \mathrm{~nm}$ on AlN-sheet submount at $350 \mathrm{~mA}$ without using an encapsulation nor the techniques of (i)-(v). Only with the use of encapsulation to the current product, more than $100 \mathrm{~mW}$ per die is considered to be sufficiently feasible by increasing LEE.

High- or ultrahigh-pressure mercury lamps have broad spectra due to the pressure broadening effect. Thus, light is wasted due to the wavelengths outside the region of interest. For example, the application of UV curing is based on a photoinduced chemical reaction, and photons with energy lower than that of the wavelength to activate the polymerizing initiator scarcely contribute to the chemical reaction, limiting the utilization factor of the light from UV bulbs. Although the WPEs of UV bulbs are as high as $10-15 \%$ for the overall emission, the total efficiency is not always high compared with that of monochromatic DUV-LEDs. Thus, encapsulated DUV-LEDs with uneven MQWs are expected to have practical applications because their lifetimes are much longer than those of UV bulbs, and their total efficiency is considered to exceed those of conventional mercury lamps.

\section{Frontiers of Current AlGaN-Based DUV-LEDs}

In Figure 1, a difficulty of the DUV-LEDs in the wavelength region where $\lambda$ is less than about $270 \mathrm{~nm}$ can be seen. The EQE rapidly decreases as the wavelength decreases from around $270 \mathrm{~nm}$. A possible reason for the low EQE $(\lambda<270 \mathrm{~nm})$ is the increased number of NRCs due to $\mathrm{V}_{\mathrm{Al}}$ with increasing AlN content. Thus, lower IQE can be one of the reasons. The decrease in the CIE also limits the LED performance due to the insufficient electrical properties of EB layer. When we performed beryllium (Be) doping using MOCVD in an attempt to improve the EB layer and low CIE, Be was not detected in the AlGaN film and no significant result was obtained. In addition to the low CIE and IQE, the polarization of light emitted from AlGaN QWs changes from transverse electric (TE) $(\mathrm{C} \perp \mathrm{E})$ to transverse magnetic (TM) $(C \| \mathrm{E})[140,141]$ at a high AlN content of around $60 \%$. TM polarization is considered to be suitable for LDs [142-144] due to the edge emitting device structure, and the control of the polarization for DUV-LEDs has also been studied [145] to solve the lowered LEE. The use of a nanorod structure [146] to extract TM light has also been studied. Moreover, very thin QWs and quantum disks (QDs) for generating TE-polarized emission at wavelengths of $\lambda<240 \mathrm{~nm}$ have been reported [147-149]. 
LEDs with emitting wavelength range between 300 and $350 \mathrm{~nm}$ appear to have lower EQEs as shown in Figure 1. The EQEs of InGaN LEDs tend to decrease with increasing wavelength away from the blue-to-NUV regions $[16,66]$ with increasing In content in InGaN. Similarly, the EQEs of AlGaN LEDs tend to decrease from $300 \mathrm{~nm}$ to $350 \mathrm{~nm}$ with increasing Ga in AlGaN. For an AlGaN-based LED with GaN wells, an EQE of $6.7 \%$ at $345 \mathrm{~nm}$ was obtained; for this LED, ELO technique was used to reduce the TDD of the $\mathrm{n}-\mathrm{AlGaN}$ cladding layer $[35,36]$. Thus, reducing the TDD is considered to be among the key methods for improving 300-350 nm LEDs if the carrier localization effect is limited due to a high $\mathrm{GaN}$ content. This wavelength region is expected to be used in the application related to the protein from the industrial viewpoint.

AlGaN-based DUV-LEDs produced by several manufacturers are already on the market. Novel uneven MQWs are an example of the application of the unexpected features of nitride materials. The mechanism of the higher EQEs by virtue of the relatively high IQEs in uneven MQWs has not yet been clarified, although the enhanced carrier localization due to macrosteps has been suggested [13]. After InGaN-based LEDs were on the market, the mechanism of the carrier localization in InGaN QWs was clarified. The study of the detailed mechanism of AlGaN-based LEDs with uneven MQWs is also expected to accelerate the improvement of LEDs.

\section{W/cm ${ }^{2}$-Class Irradiation Modules and Applications}

Figure 19a illustrates the wavelengths of interest for various applications. The wavelengths used with sensors are widely spread between $200 \mathrm{~nm}$ and $365 \mathrm{~nm}$, and two representative examples of light sources for urea sensors and high-performance liquid chromatography (HPLC) are shown. The urea sensor in a dialyzer was partially replaced by $285 \mathrm{~nm}$ DUV-LEDs and compact HPLC system is expected to be used to measure the water quality of the sewage. Among the sensor applications, these two examples are highly substantial. However, even niche semiconductor industries cannot be free from today's production machines and subcontracting companies. Sensor applications do not need a high output power and considered to be accessible market at the beginning of laboratory production. However, the number of LEDs used in sensor application is not enough, even for the niche semiconductor industries. Accordingly, an irradiation application might be the key to increasing the quantity of production. The sterilization of air and water, UV curing and printing (photochemical applications), deodorizing, the excitation of photocatalyst, phototherapy, medical applications, and so forth, should be indispensable applications for the DUV-LED industry to stand by itself. As described, an output of $100 \mathrm{~mW}$ per chip and WPE of over $7 \%$ are in sight. This means that $\mathrm{W} / \mathrm{cm}^{2}$ irradiation modules corresponding to the performance of conventional mercury-based bulbs are within reach.

Although there are some examples of LED production where LEDs with a specific wavelength are produced on demand, the range of wavelengths tends to be limited. The semiconductor industry is geared to the production of very large quantity. The spectra of conventional mercury lamps are shown in Figure 20. The advantage of LEDs to UV bulbs is thought to be located at wavelength of around 270-300 nm. For UV printing $(315 \mathrm{~nm})$ and photocatalyst excitation $(325 \mathrm{~nm})$, light sources with a shorter wavelength $(280-300 \mathrm{~nm})$ can be used because they are related to excitation. The DUV light required for UV curing has an intensity of about $0.5 \mathrm{~W} / \mathrm{cm}^{2}$. Keeping a UV printing in mind, sub-W $/ \mathrm{cm}^{2}$ modules with a dense layout of dies have been demonstrated. Figure 21 shows photographs of various irradiation modules. For sterilization, DUV-LEDs must be cost-feasible and convenient in comparison with low-pressure mercury lamps. As shown in Figure 19, the absorption of DNA occurs around $265 \mathrm{~nm}(\lambda<290 \mathrm{~nm})$. DUV-LEDs with wavelengths of $270-280 \mathrm{~nm}$ are also expected to be useful because of their high-EQE region. Light flux of about $33 \mathrm{~mW} / \mathrm{cm}^{2}$ at $254 \mathrm{~nm}$ is sufficient to kill bacteria, although there is some variation depending on bacteria. The efficiency of sterilization at $280 \mathrm{~nm}$ is more than half of that at $254 \mathrm{~nm}$ according to Figure 19b. Light flux of $1 \mathrm{~mW} / \mathrm{cm}^{2}$ at $280 \mathrm{~nm}$ for $1 \mathrm{~min}$ can kill bacteria. DUV-LEDs with a wavelength of $280 \mathrm{~nm}$ and $100 \mathrm{~mW}$ output can potentiality be used for sterilization. Accordingly, the wavelength that should be focused on mass-production is around $280-300 \mathrm{~nm}$, including sterilization or bacteriostatic applications. 
However, medical applications (310-315 nm) cannot employ shorter wavelengths owing to the need for weak absorption on the lower-energy side to avoid the destruction of genes. The advantage of using DUV-LEDs is considered to be the tunability of the wavelength and the shorter start-up time before reaching the constant output compared with discharge lamps.

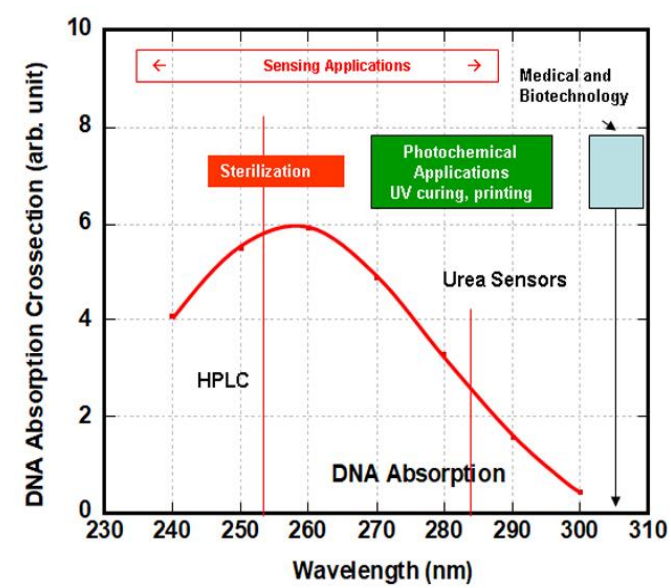

(a)

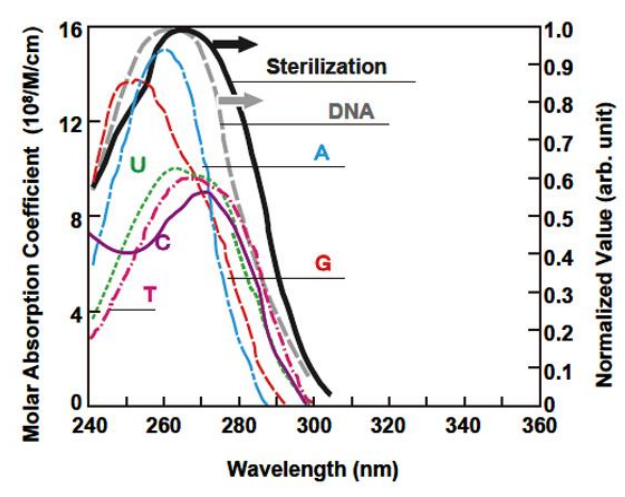

(b)

Figure 19. (a) Map of application wavelengths for DUV-LEDs; and (b) absorption of DNA, AGTC nucleic acids, uracil in ribonucleic acid, and sterilization efficiency related to their absorption. Sensor applications are expected involve various wavelengths. UV light sources in HPLC (254 nm) and urea sensors $(285 \mathrm{~nm})$ in a dialyzer are considered as examples. A larger quantity of DUV-LEDs is expected to be used for the applications of sterilization and photochemistry including UV curing. In addition, the weak excitation of proteins is useful for medical and biotechnology applications, where the wavelength used is between 305 and $315 \mathrm{~nm}$. ((a) Permitted to be reproduced from Oyobutsuri [22] ( Japan Society Applied Physics) and (b) is reproduced from Hikari Alliance [150].).

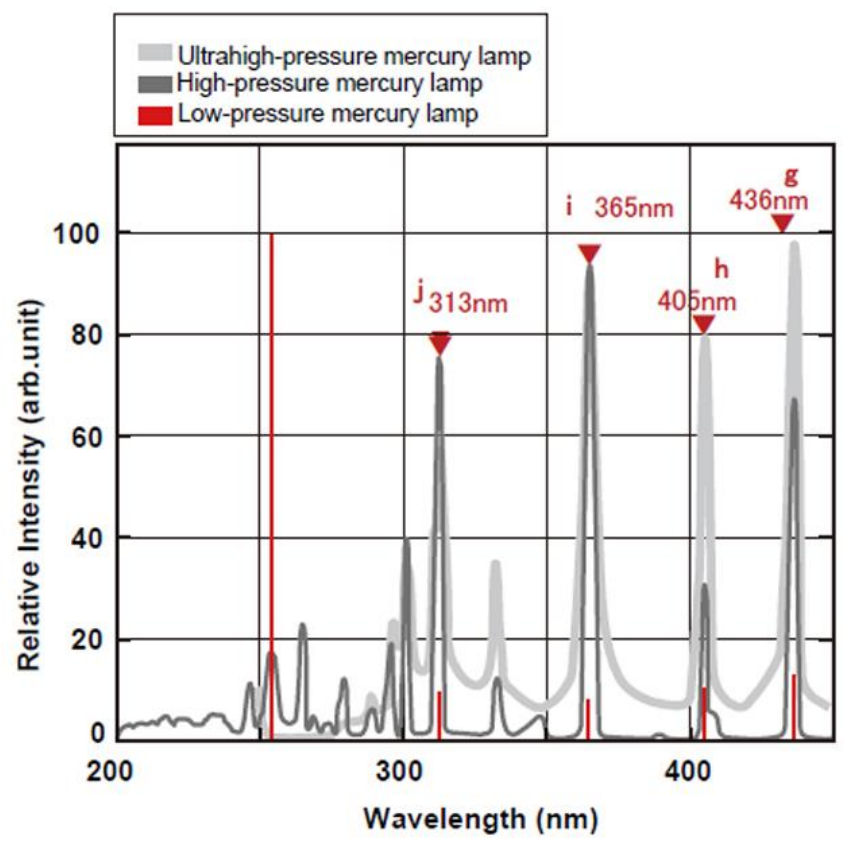

Figure 20. Spectra of low pressure (red), high-pressure (dark gray), and ultrahigh-pressure mercury lamps (light gray). The wavelength range of DUV-LEDs with high efficiency (270-300 nm) does not overlap the strong spectral lines of mercury lamps, showing the advantage of the DUV-LEDs to UV bulbs. [Permitted to be reproduced from Hikari Alliance [150].]. 
Another advantage of DUV-LEDs over UV bulbs is their weak infrared irradiation. The application of UV curing is often limited by the strong heat flux due to infrared irradiation mixed with UV light. Monochromatic DUV-LEDs are expected to reduce the damage in the UV coating of paper, polymerfilms, cloth, and wood panels.
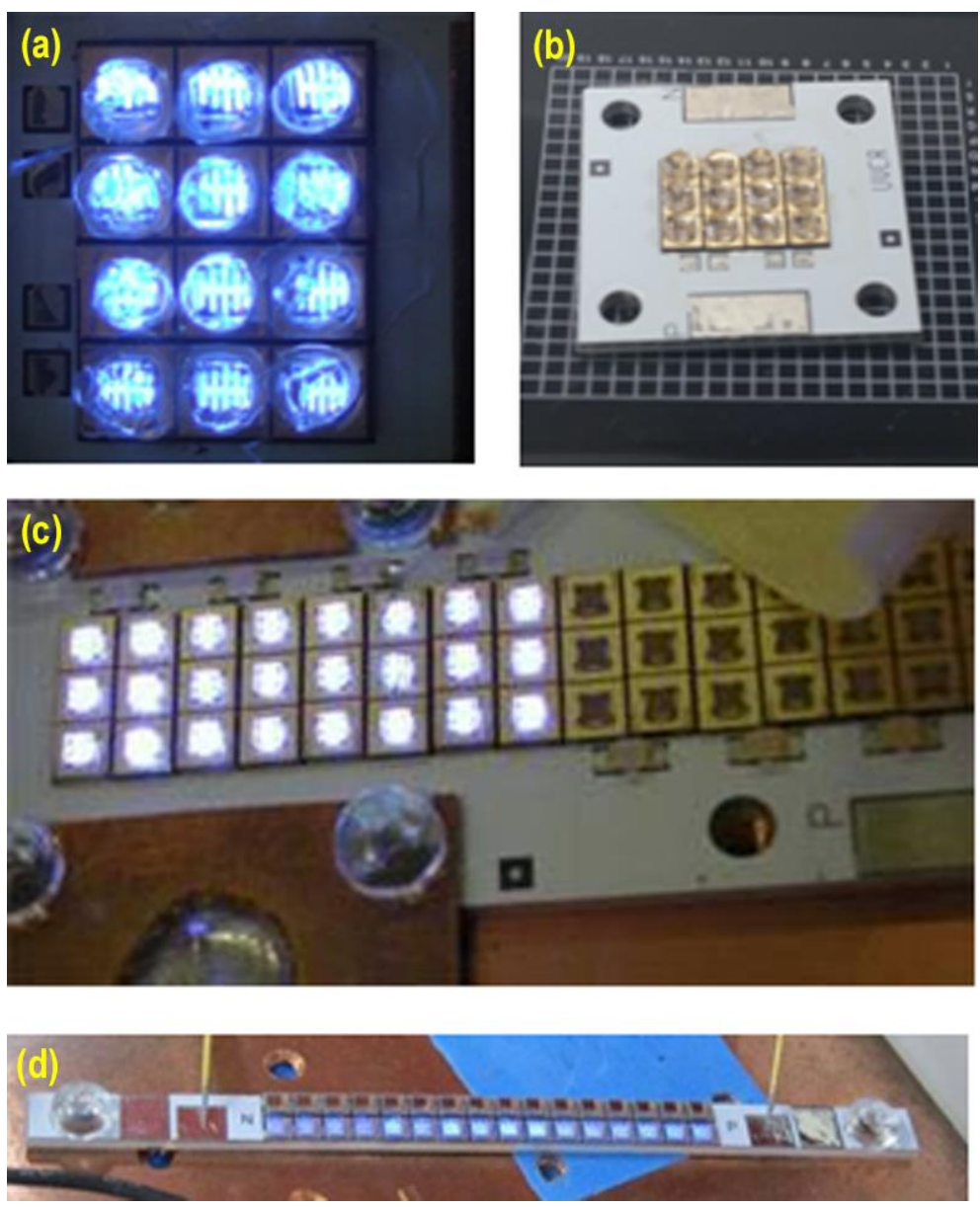

Figure 21. (a-d) Photographs of $285 \mathrm{~nm}$ irradiation modules. (a) Lighting; and (b) non-lighting $3 \times 4$ array module with encapsulation, respectively. The output power is $472 \mathrm{~mW}$ at the injected current of $200 \mathrm{~mA}$ for each die. The total AlN submount area of the 12 diode array is $10.0 \times 13.2 \mathrm{~mm}^{2}$. Modules without encapsulation: (c) photograph of $3 \times 16$ array module with dies having $3.4 \mathrm{~mm}$ pitch; and (d) LED dies with denser layout of $2.5 \mathrm{~mm}$ pitch. The die size is $1300 \times 1300 \mu \mathrm{m}^{2} .((\mathbf{a}, \mathbf{b})$ are reused from Jpn. J. Appl. Phys. [15] (@ Japan Society Applied Physics) and (c,d) are reused from Proc. SPIE 9926, 99260C (2016) [131].).

\section{General Conclusions and Future Outlook}

Owing to the insufficient crystallinity of the AlN template on a sapphire substrate, AlGaN-based DUV-LEDs had a low EL output due to the low EQE. The quality of the AlN template with a TDD of over $10^{9} / \mathrm{cm}^{2}$ was insufficient. Since the carrier localization is expected for AlGaN-based LEDs as well as for InGaN-based LEDs, a simple method of producing an AlN template with a TDD between $10^{8}$ and $10^{9} / \mathrm{cm}^{2}$ was desired. Through studies on the use of PSS, the growth of a thick layer of AlN, and the use of high-miscut sapphire, the use of high-miscut sapphire was considered to be most suitable for the mass production of AlGaN-based DUV-LEDs to obtain an AlN template with TDD on the order of $10^{8} / \mathrm{cm}^{2}$. The reasons for using high-miscut sapphire are somewhat complicated. One reason is to reduce the growth temperature to less than $1300{ }^{\circ} \mathrm{C}$. In fact, there is MOCVD equipment used 
to grow $\mathrm{SiC}$ that can be operated at $1400{ }^{\circ} \mathrm{C}$. The difference between 1300 and $1400{ }^{\circ} \mathrm{C}$ for $\mathrm{AlGaN}$ growth is caused by fluctuation of radiant heat transfer mainly from the wafer tray. When growing $\mathrm{SiC}$ devices, the compositional difference between layers is small, such as impurity in $\mathrm{SiC}$. However, during the growth of AlGaN-based LED layers, the target AlN content varies throughout the multilayer. This causes a change in the radiation rate due to the deposition inside the growth chamber, resulting in the fluctuation of the effective growth temperature even though the control temperature is fixed. Furthermore, the number of materials that can be used inside the growth chamber is limited when the growth temperature is more than $1300{ }^{\circ} \mathrm{C}$. From an industrial viewpoint, stable production is necessary and a lower growth temperature will be beneficial. In the case of a lower growth temperature, the growth time for the LED wafers tends to be longer, which is not normally desirable. A suitable balance between growth time and stable production with moderately high AlN crystallinity was found to be obtained between the temperatures of 1200 and $1300{ }^{\circ} \mathrm{C}$ in the case of high-miscut sapphire. Furthermore, the utilization of this temperature range enabled the realization of single LED wafers with a larger effective area. Fortunately, the use of high miscut sapphire resulted in a high EQE without reducing the lifetime of LEDs. We consider that the edge of the macrostep functions as a domain for carrier localization and the detailed study on such carrier localization is in progress. However, it is suggested that the thickness and the compositional modulation on the macrosteps enhanced the carrier localization. This effect unexpectedly gave the merit of achieving LEDs with higher IQE.

The device layer of DUV-LEDs is unique compared with conventional LEDs having an EL wavelength greater than $365 \mathrm{~nm}$. On the AlGaN-based EB layer, p-GaN is used, even though the incorporation of AlGaN QWs by many manufacturers and p-GaN layer seriously limit LEE. In addition, an AlGaN-based EB layer with a high AlN content limits the CIE for wavelengths shorter than $280 \mathrm{~nm}$. These problems might not be solved in short-term research. Accordingly, the use of encapsulation in addition to a thick sapphire layer is considered to be a practical solution. Despite the disadvantages of using a p-GaN layer, the WPE reached a competitive level, meaning that our device can be used as an alternative to high- and ultrahigh-pressure mercury lamps, and then Sub-W/ $\mathrm{cm}{ }^{2}$ irradiation modules for UV curing were demonstrated to be alternatives of high- and ultrahigh-pressure mercury lamps. Low-pressure mercury lamps have high efficiency and the market price is reasonable. The most important potential application of DUV-LEDs is the sterilization of air and water, which is currently performed by low-pressure mercury lamps. The performance of DUV-LEDs is not yet sufficient to be used an alternative to mercury lamps. However, a relatively short-term improvement in IQE at wavelengths of $265-280 \mathrm{~nm}$ is considered to be possible by reducing the point defect density of $\mathrm{V}_{\mathrm{Al}}$. For example, incorporating Si-doped QWs is effective to reduce the number of $\mathrm{V}_{\mathrm{Al}}$, although it is difficult to improve the CIE. From an industrial viewpoint, the authors consider that the cost-feasible production of the sterilization application is a priority; thus, the development of the larger growth apparatus and cost-feasible packaging should be tackled as priority tasks.

Author Contributions: All the authors have participated in the literature review and in the correction and revision of the manuscript.

Funding: This research received no external funding.

Conflicts of Interest: The authors declare that there are conflicts of interest between the manufacturers of AlGaN-based DUV-LEDs. Therefore, researchers of the institutes having a grant from DUV-LED manufactuers might be involved in the conflicts of interest, because business of DUV-LEDs started recently.

\section{References}

1. Rattanakul, S.; Oguma, K. Inactivation kinetics and efficiencies of UV-LEDs against Pseudomonas aeruginosa, Legionella pneumophila, and surrogate microorganisms. Water Res. 2018, 130, 31-37. [CrossRef] [PubMed]

2. Rattanakul, S.; Oguma, K. Analysis of Hydroxyl Radicals and Inactivation Mechanisms of Bacteriophage MS2 in Response to a Simultaneous Application of UV and Chlorine. Environ. Sci. Technol. 2017, 51, 455-462. [CrossRef] [PubMed] 
3. Zhou, X.; Li, Z.; Lan, J.; Yan, Y.; Zhu, N. Kinetics of inactivation and photoreactivation of Escherichia coli using ultrasound-enhanced UV-C light-emitting diodes disinfection. Ultrason. Sonochem. 2017, 35, 471-477. [CrossRef] [PubMed]

4. Gassie, L.W.; Englehardt, J.D. Advanced oxidation and disinfection processes for onsite net-zero greywater reuse: A review. Water Res. 2017, 125, 384-399. [CrossRef] [PubMed]

5. Okamura, H.; Niizeki, S.; Ochi, T.; Matsumoto, A. UV Curable Formulations for UV-C LEDs. J. Photopolym. Sci. Technol. 2016, 29, 99-104. [CrossRef]

6. Okamura, H.; Matoba, T.; Takada, K.; Yamashita, M.; Shirai, M.; Matsumoto, A. Photo-thermal Dual Curing of Acrylic Anchor Resins for Screen Printing. Progr. Org. Coat. 2016, 100, 47-50. [CrossRef]

7. Murakmi, M.; Morita, A.; Seite, S.; Haamann-Stermann, T.; Grether-Beck, S.; Krutmann, J. Environmentinduced lentigines: Formation of solar lentigines beyond ultraviolet radiation. Exp. Dermatol. 2015, 24, 407-411. [CrossRef]

8. Yamazaki, S.; Nishioka, A.; Kasuya, S.; Ohkura, N.; Hemmi, H.; Kaisho, T.; Taguchi, O.; Sakaguchi, S.; Morita, A. Homeostasis of Thymus-Derived Foxp3(+) Regulatory T Cells Is Controlled by Ultraviolet B Exposure in the Skin. J. Immunol. 2014, 193, 5488-5497. [CrossRef] [PubMed]

9. Fujishima, A.; Zhang, X.T. Titanium dioxide photocatalysis: Present situation and future approaches. C. R. Chim. 2006, 9, 750-760. [CrossRef]

10. Fujishima, A.; Rao, T.N.; Tryk, D.A. Titanium dioxide photocatalysis. J. Photochem. Photobiol. C Photochem. Rev. 2000. [CrossRef]

11. Tomson, R.; Uhlin, F.; Fridolin, I. Urea Rebound Assessment Based on UV Absorbance in Spent Dialysate. Asaio J. 2014, 60, 459-465. [CrossRef] [PubMed]

12. Uhlin, F.; Fridolin, I.; Lindberg, L.G.; Magnusson, M. Estimating total urea removal and protein catabolic rate by monitoring UV absorbance in spent dialysate. Nephrol. Dial. Transp. 2005, 20, 2458-2464. [CrossRef] [PubMed]

13. Kaneda, M.; Pernot, C.; Nagasawa, Y.; Hirano, A.; Ippommatsu, M.; Honda, Y.; Amano, H.; Akasaki, I. Uneven AlGaN multiple quantum well for deep-ultraviolet LEDs grown on macrosteps and impact on electroluminescence spectral output. Jpn. J. Appl. Phys. 2017, 56, 061002. [CrossRef]

14. Yamada, K.; Furusawan, Y.; Nagai, S.; Hirano, A.; Ippommatsu, M.; Aosaki, K.; Morishima, N.; Amano, H.; Akasaki, I. Development of underfilling and encapsulation for deep-ultraviolet LEDs. Appl. Phys. Express 2015, 8, 012101. [CrossRef]

15. Nagai, S.; Yamada, K.; Hirano, A.; Ippommatsu, M.; Ito, M.; Morishima, N.; Aosaki, K.; Honda, Y.; Amano, H.; Akasaki, I. Development of highly durable deep-ultraviolet AlGaN-based LED multichip array with hemispherical encapsulated structures using a selected resin through a detailed feasibility study. Jpn. J. Appl. Phys. 2016, 55, 082101. [CrossRef]

16. Kneissl, M. A Brief Review of III-Nitride UV Emitter Technologies and Their Applications. In III-Nitride Ultraviolet Emitters; Kneissl, M., Rass, J., Eds.; Springer International Publishing AG: Cham, Switzerland, 2016; pp. 1-25, ISBN 978-3-319-24100-5.

17. Grandusky, J.R.; Chen, J.F.; Gibb, S.R.; Mendrick, M.C.; Moe, C.G.; Rodak, L.; Garrett, G.A.; Wraback, M.; Schowalter, L.J. $270 \mathrm{~nm}$ Pseudomorphic Ultraviolet Light-Emitting Diodes with Over $60 \mathrm{~mW}$ Continuous Wave Output Power. Appl. Phys. Express 2013, 6, 032101. [CrossRef]

18. Inoue, S.; Naoki, T.; Kinoshita, T.; Obata, T.; Yanagi, H. Light extraction enhancement of $265 \mathrm{~nm}$ deep-ultraviolet light-emitting diodes with over $90 \mathrm{~mW}$ output power via an AlN hybrid nanostructure. Appl. Phys. Lett. 2015, 106, 131104. [CrossRef]

19. Fujioka, A.; Asada, K.; Yamada, H.; Ohtsuka, T.; Ogawa, T.; Kosugi, T.; Kishikawa, D.; Mukai, T. High-output-power 255/280/310 nm deep ultraviolet light-emitting diodes and their lifetime characteristics. Semicond. Sci. Technol. 2014, 29, 084005. [CrossRef]

20. Ichikawa, M.; Fujioka, A.; Kosugi, T.; Endo, S.; Sagawa, H.; Tamaki, H.; Mukai, T.; Uomoto, M.; Shimatsu, T. High-output-power deep ultraviolet light-emitting diode assembly using direct bonding. Appl. Phys. Express 2016, 9, 072101. [CrossRef]

21. Takano, T.; Mino, T.; Sakai, J.; Noguchi, N.; Tsubaki, K.; Hirayama, H. Deep-ultraviolet light-emitting diodes with external quantum efficiency higher than $20 \%$ at $275 \mathrm{~nm}$ achieved by improving light-extraction efficiency. Appl. Phys. Express 2017, 10, 031002. [CrossRef] 
22. Hirano, A.; Ippommatsu, M. Tanpachou shigaisen LED no jitsuyouka. Oyobutsuri 2017, 86, $234-237$. (In Japanese)

23. Chitnis, A.; Zhang, J.P.; Adivarahan, V.; Shatalov, M.; Wu, S.; Pachipulusu, R.; Mandavilli, V.; Khan, M.A. Improved performance of 325-nm emission AlGaN ultraviolet light-emitting diodes. Appl. Phys. Lett. 2003, 82, 2565-2567. [CrossRef]

24. Shatalov, M.; Sun, W.H.; Jain, R.; Lunev, A.; Hu, X.H.; Dobrinsky, A.; Bilenko, Y.; Yang, J.W.; Garrett, G.A.; Rodak, L.E.; et al. High power AlGaN ultraviolet light emitters. Semicond. Sci. Technol. 2014, $29,084007$. [CrossRef]

25. Shatalov, M.; Sun, W.H.; Lunev, A.; Hu, X.H.; Dobrinsky, A.; Bilenko, Y.; Yang, J.W.; Shur, M.; Gaska, R.; Moe, C.; Garrett, G.; Wraback, M. AlGaN Deep-Ultraviolet Light-Emitting Diodes with External Quantum Efficiency above 10\%. Appl. Phys. Express 2012, 5, 082101. [CrossRef]

26. Shatalov, M.; Sun, W.H.; Bilenko, Y.; Sattu, A.; Hu, X.H.; Deng, J.Y.; Yang, J.W.; Shur, M.; Moe, C.; Wraback, M.; Gaska, R. Large Chip High Power Deep Ultraviolet Light-Emitting Diodes. Appl. Phys. Express 2010, 3, 062101. [CrossRef]

27. Hwang, S.; Morgan, D.; Kesler, A.; Lachab, M.; Zhang, B.; Heidari, A.; Nazir, H.; Ahmad, I.; Dion, J.; Fareed, Q.; et al. $276 \mathrm{~nm}$ Substrate-Free Flip-Chip AlGaN Light-Emitting Diodes. Appl. Phys. Express 2011, 4, 032102. [CrossRef]

28. Hwang, S.; Islam, M.; Zhang, B.; Lachab, M.; Dion, J.; Heidari, A.; Nazir, H.; Adivarahan, V.; Khan, A. A Hybrid Micro-Pixel Based Deep Ultraviolet Light-Emitting Diode Lamp. Appl. Phys. Express 2011, 4, 012102. [CrossRef]

29. Grandusky, J.R.; Gibb, S.R.; Mendrick, M.C.; Moe, C.; Wraback, M.; Schowalter, L.J. High Output Power from 260nm Pseudomorphic Ultraviolet Light-Emitting Diodes with Improved Thermal Performance. Appl. Phys. Express 2011, 4, 082101. [CrossRef]

30. Kinoshita, T.; Obata, T.; Nagashima, T.; Yanagi, H.; Moody, B.; Mita, S.; Inoue, S.; Kumagai, Y.; Koukitu, A.; Sitar, Z. Performance and Reliability of Deep-Ultraviolet Light-Emitting Diodes Fabricated on AlN Substrates Prepared by Hydride Vapor Phase Epitaxy. Appl. Phys. Express 2013, 6, 092103. [CrossRef]

31. Imura, M.; Nakano, K.; Narita, G.; Fujimoto, N.; Okada, N.; Balakrishnan, K.; Iwaya, M.; Kamiyama, S.; Amano, H.; Akasaki, I.; et al. Epitaxial lateral overgrowth of AlN on trench-patterned AlN layers. J. Cryst. Growth 2007, 298, 257-260. [CrossRef]

32. Kato, N.; Sato, S.; Sumii, T.; Fujimoto, N.; Okada, N.; Imura, M.; Balakrishnan, K.; Iwaya, M.; Kamiyama, S.; Amano, H.; et al. High-speed growth of AlGaN having high-crystalline quality and smooth surface by high-temperature MOVPE. J. Cryst. Growth 2007, 298, 215-218. [CrossRef]

33. Okada, N.; Kato, N.; Sato, S.; Sumii, T.; Fujimoto, N.; Imura, M.; Balakrishnan, K.; Iwaya, M.; Kamiyama, S.; Amano, H.; et al. Epitaxial lateral overgrowth of a-AlN layer on patterned a-AlN template by HT-MOVPE. J. Cryst. Growth 2007, 300, 141-144. [CrossRef]

34. Nagamatsu, K.; Okada, N.; Sugimura, H.; Tsuzuki, H.; Mori, F.; Iida, K.; Bando, A.; Iwaya, M.; Kamiyama, S.; Amano, H.; et al. High-efficiency AlGaN-based UV light-emitting diode on laterally overgrown AlN. J. Cryst. Growth 2008, 310, 2326-2329. [CrossRef]

35. Tsuzuki, H.; Mori, F.; Takeda, K.; Ichikawa, T.; Iwaya, M.; Kamiyama, S.; Amano, H.; Akasaki, I.; Yoshida, H.; Kuwabara, M.; et al. High-performance UV emitter grown on high-crystalline-quality AlGaN underlying layer. Phys. Stat. Solidi A 2009, 206, 1199-1204. [CrossRef]

36. Tsuzuki, H.; Mori, F.; Takeda, K.; Iwya, M.; Kamiyama, S.; Amano, H.; Akasaki, I.; Yoshida, H.; Kuwabara, M.; Yamashita, Y.; et al. Novel UV devices on high-quality AlGaN using grooved underlying layer. J. Cryst. Growth 2009, 311, 2860-2863. [CrossRef]

37. Pernot, C.; Kim, M.; Fukahori, S.; Inazu, T.; Fujita, T.; Nagasawa, Y.; Hirano, A.; Ippommatsu, M.; Iwaya, M.; Kamiyama, S.; et al. Improved Efficiency of 255-280 nm AlGaN-Based Light-Emitting Diodes. Appl. Phys. Express 2010, 3, 061004. [CrossRef]

38. Pernot, C.; Fukahori, S.; Inazu, T.; Fujita, T.; Kim, M.; Nagasawa, Y.; Hirano, A.; Ippommatsu, M.; Iwaya, M.; Kamiyama, S.; et al. Development of high efficiency 255-355nm AlGaN-based light-emitting diodes. Phys. Stat. Solidi A 2011, 208, 1594-1596. [CrossRef]

39. Kim, M.; Fujita, T.; Fukahori, S.; Inazu, T.; Pernot, C.; Nagasawa, Y.; Hirano, A.; Ippommatsu, M.; Iwaya, M.; Takeuchi, T.; et al. AlGaN-Based Deep Ultraviolet Light-Emitting Diodes Fabricated on Patterned Sapphire Substrates. Appl. Phys. Express 2011, 4, 092102. [CrossRef] 
40. Inazu, T.; Fukahori, S.; Pernot, C.; Kim, M.H.; Fujita, T.; Nagasawa, Y.; Hirano, A.; Ippommatsu, M.; Iwaya, M.; Takeuchi, T.; et al. Improvement of Light Extraction Efficiency for AlGaN-Based Deep Ultraviolet Light-Emitting Diodes. Jpn. J. Appl. Phys. 2011, 50, 122101. [CrossRef]

41. Hirayama, H.; Maeda, N.; Fujikawa, S.; Toyoda, S.; Kamata, N. Recent progress and future prospects of AlGaN-based high-efficiency deep-ultraviolet light-emitting diodes. Jpn. J. Appl. Phys. 2014, 53, 100209. [CrossRef]

42. Jo, M.; Maeda, N.; Hirayama, H. Enhanced light extraction in $260 \mathrm{~nm}$ light-emitting diode with a highly transparent p-AlGaN layer. Appl. Phys. Express 2016, 9, 012102. [CrossRef]

43. Kashima, Y.; Maeda, N.; Matsuura, E.; Jo, M.; Iwai, T.; Morita, T.; Kokubo, M.; Tashiro, T.; Kamimura, R.; Osada, Y.; et al. High external quantum efficiency (10\%) AlGaN-based deep-ultraviolet light-emitting diodes achieved by using highly reflective photonic crystal on p-AlGaN contact layer. Appl. Phys. Express 2018, 11, 012101. [CrossRef]

44. Hirayama, H.; Noguchi, N.; Kamata, N. 222 nm Deep-Ultraviolet AlGaN Quantum Well Light-Emitting Diode with Vertical Emission Properties. Appl. Phys. Express 2010, 3, 032102. [CrossRef]

45. Hirayama, H.; Tsukada, Y.; Maeda, T.; Kamata, N. Marked Enhancement in the Efficiency of Deep-Ultraviolet AlGaN Light-Emitting Diodes by Using a Multiquantum-Barrier Electron Blocking Layer. Appl. Phys. Express 2010, 3, 031002. [CrossRef]

46. Fujioka, A.; Misaki, T.; Murayama, T.; Narukawa, Y.; Mukai, T. Improvement in Output Power of 280-nm Deep Ultraviolet Light-Emitting Diode by Using AlGaN Multi Quantum Wells. Appl. Phys. Express 2010, 3, 041001. [CrossRef]

47. Susilo, N.; Hagedorn, S.; Jaeger, D.; Miyake, H.; Zeimer, U.; Reich, C.; Neuschulz, B.; Sulmoni, L.; Guttmann, M.; Mehnke, F.; Kuhn, C.; et al. AlGaN-based deep UV LEDs grown on sputtered and high temperature annealed AlN/sapphire. Appl. Phys. Lett. 2018, 112, 041110. [CrossRef]

48. Enslin, J.; Mehnke, F.; Mogilatenko, A.; Bellmann, K.; Guttmann, M.; Kuhn, C.; Rass, J.; Lobo-Ploch, N.; Wernicke, T.; Weyers, M.; et al. Metamorphic $\mathrm{Al}_{0.5} \mathrm{Ga}_{0.5} \mathrm{~N}$ :Si on AlN/sapphire for the growth of UVB LEDs. J. Cryst. Growth 2017, 464, 185-189. [CrossRef]

49. Mehnke, F.; Kuhn, C.; Guttmann, M.; Reich, C.; Kolbe, T.; Kueller, V.; Knauer, A.; Lapeyrade, M.; Einfeldt, S.; Rass, J.; et al. Efficient charge carrier injection into sub-250nm AlGaN multiple quantum well light emitting diodes. Appl. Phys. Lett. 2014, 105, 051113. [CrossRef]

50. Lee, K.H.; Park, H.J.; Kim, S.H.; Asadirad, M.; Moon, Y.T.; Kwak, J.S.; Ryou, J.H. Light-extraction efficiency control in AlGaN-based deep-ultraviolet flip-chip light-emitting diodes: A comparison to InGaN-based visible flip-chip light-emitting diodes. Opt. Express 2015, 23, 20340-20349. [CrossRef] [PubMed]

51. Fayisa, G.B.; Lee, J.W.; Kim, J.; Kim, Y.I.; Park, Y.; Kim, J.K. Enhanced light extraction efficiency of micro-ring array AlGaN deep ultraviolet light-emitting diodes. Jpn. J. Appl. Phys. 2017, 56, 092101. [CrossRef]

52. Lee, D.; Lee, J.W.; Jang, J.; Shin, I.S.; Jin, L.; Park, J.H.; Kim, J.; Lee, J.; Noh, H.S.; Kim, Y.I.; et al. Improved performance of AlGaN-based deep ultraviolet light-emitting diodes with nano-patterned AlN/sapphire substrates. Appl. Phys. Lett. 2017, 110, 191103. [CrossRef]

53. Yue, J.S.; Gao, Y.; Zhang, G.H.; Liu, Y. Light power enhancement of violet LEDs using AlGaN-based epitaxial structure. Appl. Mech. Mater. 2013, 331, 572-577. [CrossRef]

54. Wu, J. High Power High Efficiency DUV LEDs and Applications. Presented at LED TAIWAN 2016, Taipei, Taiwan, 14 April 2016.

55. Zhou, T.Y.; Raghothamachar, B.; Wu, F.Z.; Dalmau, R.; Moody, B.; Craft, S.; Schlesser, R.; Dudley, M.; Sitar, Z. Characterization of Threading Dislocations in PVT-Grown AlN Substrates via x-Ray Topography and Ray Tracing Simulation. J. Electron. Mater. 2014, 43, 838-842. [CrossRef]

56. Bondokov, R.T.; Mueller, S.G.; Morgan, K.E.; Slack, G.A.; Schujman, S.; Wood, M.C.; Smart, J.A.; Schowalter, L.J. Large-area AlN substrates for electronic applications: An industrial perspective. J. Cryst. Growth 2008, 310, 4020-4026. [CrossRef]

57. Schowalter, L.J.; Schujman, S.B.; Liu, W.; Goorsky, M.; Wood, M.C.; Grandusky, J.; Shahedipour-Sandvik, F. Development of native, single crystal AlN substrates for device applications. Phys. Stat. Solidi A 2006, 203, 1667-1671. [CrossRef]

58. Collazo, R.; Xie, J.Q.; Gaddy, B.E.; Bryan, Z.; Kirste, R.; Hoffmann, M.; Dalmau, R.; Moody, B.; Kumagai, Y.; Nagashima, T.; et al. On the origin of the $265 \mathrm{~nm}$ absorption band in AlN bulk crystals. Appl. Phys. Lett. 2012, 100, 191914. [CrossRef] 
59. Slack, G.A.; Schowalter, L.J.; Morelli, D.; Freitas, J.A. Some effects of oxygen impurities on AlN and GaN. J. Cryst. Growth 2002, 246, 287-298. [CrossRef]

60. Bryan, Z.; Bryan, I.; Xie, J.Q.; Mita, S.; Sitar, Z.; Collazo, R. High internal quantum efficiency in AlGaN multiple quantum wells grown on bulk AlN substrates. Appl. Phys. Lett. 2015, 106, 142107. [CrossRef]

61. Moe, C.G.; Garrett, G.A.; Grandusky, J.R.; Chen, J.F.; Rodak, L.E.; Rotella, P.; Wraback, M.; Schowalter, L.J. Correlation between optical and electrical performance of mid-ultraviolet light-emitting diodes on AlN substrates. Phys. Stat. Solidi C 2014, 11, 786-789. [CrossRef]

62. Grandusky, J.R.; Gibb, S.R.; Mendrick, M.; Schowalter, L.J. Reliability and performance of pseudomorphic ultraviolet light emitting diodes on bulk aluminum nitride substrates. Phys. Statud Solidi C 2011, 8, 1528-1533. [CrossRef]

63. Nakamura, S.; Mukai, T. High-quality InGaN films grown on GaN films. Jpn. J. Appl. Phys. 1992, 31, L1457-L1459. [CrossRef]

64. Nakamura, S.; Senoh, M.; Mukai, T. High-power InGaN/GaN double-heterostructure violet-lightemitting-diodes. Appl. Phys. Lett. 1993, 62, 2390-2392. [CrossRef]

65. Nakamura, S.; Mukai, T.; Senoh, M. High-brightness InGaN/AlGaN double-heterostructure blue-green-light emitting diodes. J. Appl. Phys. 1994, 76, 8189-8191. [CrossRef]

66. Nakamura, S.; Senoh, N.; Iwasa, N.; Nagashima, S. High-brightness InGaN blue, green and yellow light-emitting-diodes with quantum-well strucrtures. Jpn. J. Appl. Phys. 1995, 34, L797-L799. [CrossRef]

67. Nakamura, S.; Senoh, M.; Nagahama, S.; Iwasa, N.; Yamada, T.; Matsushita, T.; Sugimoto, Y.; Kiyoku, H. Room-temperature continuous-wave operation of InGaN multi-quantum-well structure laser diodes. Appl. Phys. Lett. 1996, 69, 4056-4058. [CrossRef]

68. Nakamura, S.; Senoh, M.; Nagahama, S.; Iwasa, N.; Yamada, T.; Matsushita, T.; Kiyoku, H.; Sugimoto, Y.; Kozaki, T.; Umemoto, H.; et al. Violet InGaN/GaN/AlGaN-based laser diodes with an output power of 420 mW. Jpn. J. Appl. Phys. 1998, 37, L627-L629. [CrossRef]

69. Zhang, J.P.; Khan, M.A.; Sun, W.H.; Wang, H.M.; Chen, C.Q.; Fareed, Q.; Kuokstis, E.; Yang, J.W. Pulsed atomic-layer epitaxy of ultrahigh-quality AlxGa1-xN structures for deep ultraviolet emissions below $230 \mathrm{~nm}$. Appl. Phys. Lett. 2002, 81, 4392-4394. [CrossRef]

70. Hirayama, H.; Yatabe, T.; Noguchi, N.; Ohashi, T.; Kamata, N. 231-261 nm AlGaN deep-ultraviolet light-emitting diodes fabricated on AIN multilayer buffers grown by ammonia pulse-flow method on sapphire. Appl. Phys. Lett. 2007, 91, 071901. [CrossRef]

71. Banal, R.G.; Funato, M.; Kawakami, Y. Growth characteristics of AlN on sapphire substrates by modified migration-enhanced epitaxy. J. Cryst. Growth 2009, 311, 2834-2836. [CrossRef]

72. Imura, M.; Nakano, K.; Fujimoto, N.; Okada, N.; Balakrishnan, K.; Iwaya, M.; Kamiyama, S.; Amano, H.; Akasaki, I.; Noro, T.; et al. Dislocations in AIN epilayers grown on sapphire substrate by high-temperature metal-organic vapor phase epitaxy. Jpn. J. Appl. Phys. 2007, 46, 1458-1462. [CrossRef]

73. Balakrishnan, K.; Bandoh, A.; Iwaya, M.; Kamiyama, S.; Amano, H.; Akasaki, I. Influence of high temperature in the growth of low dislocation content AlN bridge layers on patterned $6 \mathrm{H}-\mathrm{SiC}$ substrates by metalorganic vapor phase epitaxy. Jpn. J. Appl. Phys. 2007, 46, L307-L310. [CrossRef]

74. Miyake, H.; Nishio, G.; Suzuki, S.; Hiramatsu, K.; Fukuyama, H.; Kaur, J.; Kuwano, N. Annealing of an AlN buffer layer in N-2-CO for growth of a high-quality AlN film on sapphire. Appl. Phys. Express 2016, 9, 025501. [CrossRef]

75. Fukuyama, H.; Miyake, H.; Nishio, G.; Suzuki, S.; Hiramatsu, K. Impact of high-temperature annealing of AlN layer on sapphire and its thermodynamic principle. Jpn. J. Appl. Phys. 2016, 55, 05FL02. [CrossRef]

76. Miyake, H.; Lin, C.H.; Tokoro, K.; Hiramatsu, K. Preparation of high-quality AlN on sapphire by high-temperature face-to-face annealing. J. Cryst. Growth 2016, 456, 155-159. [CrossRef]

77. Ban, K.; Yamamoto, J.; Takeda, K.; Ide, K.; Iwaya, M.; Takeuchi, T.; Kamiyama, S.; Akasaki, I.; Amano, H. Internal Quantum Efficiency of Whole-Composition-Range AlGaN Multiquantum Wells. Appl. Phys. Express 2011, 4, 052101. [CrossRef]

78. Ren, Z.Y.; Sun, Q.; Kwon, S.Y.; Han, J.; Davitt, K.; Song, Y.K.; Nurmikko, A.V.; Liu, W.; Smart, J.; Schowalter, L. AlGaN deep ultraviolet LEDs on bulk AIN substrates. Heteroepitaxy of AlGaN on bulk AlN substrates for deep ultraviolet light emitting diodes. Phys. Status Solidi C 2007, 4, 2482-2485. [CrossRef] 
79. Ren, Z.; Sun, Q.; Kwon, S.Y.; Han, J.; Davitt, K.; Song, Y.K.; Nurmikko, A.V.; Cho, H.K.; Liu, W.; Smart, J.A.; Schowalter, L.J. Heteroepitaxy of AlGaN on bulk AlN substrates for deep ultraviolet light emitting diodes. Appl. Phys. Lett. 2007, 91, 051116. [CrossRef]

80. Grandusky, J.R.; Smart, J.A.; Mendrick, M.C.; Schowalter, L.J.; Chen, K.X.; Schubert, E.F. Pseudomorphic growth of thick n-type AlxGa1-xN layers on low-defect-density bulk AlN substrates for UV LED applications. J. Cryst. Growth 2009, 311, 2864-2866. [CrossRef]

81. Chichibu, S.F.; Miyake, H.; Hiramtsu, K.; Uedono, A. Impacts of Dislocations and Point Defects on the Internal Quantum Efficiency of the Near-Band-Edge Emission in AlGaN-Based DUV Light-Emitting Materials. In III-Nitride Ultraviolet Emitters: Technology and Applications; Kneissl, M., Rass, J., Eds.; Springer: Berlin, Germany, 2016; Volume 227, pp. 115-136, ISBN 978-3-319-24100-5.

82. Chichibu, S.F.; Miyake, H.; Ishikawa, Y.; Tashiro, M.; Ohtomo, T.; Furusawa, K.; Hazu, K.; Hiramatsu, K.; Uedono, A. Impacts of Si-doping and resultant cation vacancy formation on the luminescence dynamics for the near-band-edge emission of Al0.6Ga0.4N films grown on AlN templates by metalorganic vapor phase epitaxy. J. Appl. Phys. 2013, 113, 213506. [CrossRef]

83. Chichibu, S.F.; Wada, K.; Mullhauser, J.; Brandt, O.; Ploog, K.H.; Mizutani, T.; Setoguchi, A.; Nakai, R.; Sugiyama, M.; Nakanishi, H.; et al. Evidence of localization effects in InGaN single-quantum-well ultraviolet light-emitting diodes. Appl. Phys. Lett. 2000, 76, 1671-1673. [CrossRef]

84. Chichibu, S.F.; Azuhata, T.; Sota, T.; Mukai, T.; Nakamura, S. Localized quantum well excitons in InGaN single-quantum-well amber light-emitting diodes. J. Appl. Phys. 2000, 88, 5153-5157. [CrossRef]

85. Chichibu, S.; Wada, K.; Nakamura, S. Spatially resolved cathodoluminescence spectra of InGaN quantum wells. Appl. Phys. Lett. 1997, 71, 2346-2348. [CrossRef]

86. Murotani, H.; Yamada, Y.; Taguchi, T.; Ishibashi, A.; Kawaguchi, Y.; Yokogawa, T. Temperature dependence of localized exciton transitions in AlGaN ternary alloy epitaxial layers. J. Appl. Phys. 2008, 104, 053514. [CrossRef]

87. Murotani, H.; Saito, T.; Kato, N.; Yamada, Y.; Taguchi, T. Localization-induced inhomogeneous screening of internal electric fields in AlGaN-based quantum wells. Appl. Phys. Lett. 2007, 91, 231910. [CrossRef]

88. Murotani, H.; Yamada, Y.; Taguchi, T.; Kato, R.; Yokogawa, T. Exciton localization in Al-rich AlGaN ternary alloy epitaxial layers. Phys. Status Solidi C 2010, 7, 7-8. [CrossRef]

89. Murotani, H.; Akase, D.; Anai, K.; Yamada, Y.; Miyake, H.; Hiramatsu, K. Dependence of internal quantum efficiency on doping region and Si concentration in Al-rich AlGaN quantum wells. Appl. Phys. Lett. 2012, 101, 042110. [CrossRef]

90. Amano, H.; Sawaki, N.; Akasaki, I. Metalorganic vapor phase epitaxial growth of high quality GaN film using an AlN buffer layer. Appl. Phys. Lett. 1986, 48, 353-355. [CrossRef]

91. Nakamura, S. GaN growth using GaN buffer layer. Jpn. J. Appl. Phys. 1991, 30, L1705-L1707. [CrossRef]

92. Nakamura, S.; Senoh, M.; Nagahama, S.; Iwasa, N.; Yamada, T.; Matsushita, T.; Kiyoku, H.; Sugimoto, Y.; Kozaki, T.; Umemoto, H.; et al. High-power, long-lifetime InGaN/GaN/AlGaN-based laser diodes grown on pure GaN substrates. Jpn. J. Appl. Phys. 1998, 37, L309-L312. [CrossRef]

93. Linthicum, K.; Gehrke, T.; Thomson, D.; Carlson, E.; Rajagopal, P.; Smith, T.; Batchelor, D.; Davis, R. Pendeoepitaxy of gallium nitride thin films. Appl. Phys. Lett. 1999, 75, 196-198. [CrossRef]

94. Bohyama, S.; Miyake, H.; Hiramatsu, K.; Tsuchida, Y.; Maeda, T. Freestanding GaN substrate by advanced facet-controlled epitaxial lateral overgrowth technique with masking side facets. Jpn. J. Appl. Phys. 2005, 44, L24-L26. [CrossRef]

95. Zhou, S.Z.; Wang, H.Y.; Lin, Z.T.; Yang, H.; Hong, X.S.; Li, G.Q. Study of defects in LED epitaxial layers grown on the optimized hemispherical patterned sapphire substrates. Jpn. J. Appl. Phys. 2014, 53, 025503. [CrossRef]

96. Jeong, S.M.; Kissinger, S.; Kim, D.W.; Lee, S.J.; Kim, J.S.; Ahn, H.K.; Lee, C.R. Characteristic enhancement of the blue LED chip by the growth and fabrication on patterned sapphire (0001) substrate. J. Cryst. Growth 2010, 312, 258-262. [CrossRef]

97. Motoki, K.; Okahisa, T.; Matsumoto, N.; Matsushima, M.; Kimura, H.; Kasai, H.; Takemoto, K.; Uematsu, K.; Hirano, T.; Nakayama, M.; et al. Preparation of large freestanding GaN substrates by hydride vapor phase epitaxy using GaAs as a starting substrate. Jpn. J. Appl. Phys. 2001, 40, L140-L143. [CrossRef]

98. Motoki, K.; Okahisa, T.; Nakahata, S.; Matsumoto, N.; Kimura, H.; Kasai, H.; Takemoto, K.; Uematsu, K.; Ueno, M.; Kumagai, Y.; et al. Growth and characterization of freestanding GaN substrates. J. Cryst. Growth 2002, 237, 912-921. [CrossRef] 
99. Chitnis, A.; Adivarahan, V.; Zhang, J.P.; Shatalov, M.; Wu, S.; Yang, J.; Simin, G.; Khan, M.A.; Hu, X.; Fareed, Q.; et al. Milliwatt power AlGaN quantum well deep ultraviolet light emitting diodes. Phys. Status Solidi A 2003, 200, 99-101. [CrossRef]

100. Chen, Z.; Fareed, R.S.Q.; Gaevski, M.; Adivarahan, V.; Yang, J.W.; Khan, A.; Mei, J.; Ponce, F.A. Pulsed lateral epitaxial overgrowth of aluminum nitride on sapphire substrates. Appl. Phys. Lett. 2006, 89, 081905. [CrossRef]

101. Nakano, K.; Imura, M.; Narita, G.; Kitano, T.; Hirosel, Y.; Fujimoto, N.; Okada, N.; Kawashima, T.; Iida, K.; Balakrishnan, K.; et al. Epitaxial lateral overgrowth of AlN layers on patterned sapphire substrates. Phys. Status Solidi A 2006, 203, 1632-1635. [CrossRef]

102. Tran, B.T.; Hirayama, H.; Jo, M.; Maeda, N.; Inoue, D.; Kikitsu, T. High-quality AlN template grown on a patterned $\mathrm{Si}(111)$ substrate. J. Cryst. Growth 2017, 468, 225-229. [CrossRef]

103. Tran, B.T.; Maeda, N.; Jo, M.; Inoue, D.; Kikitsu, T.; Hirayama, H. Performance Improvement of AIN Crystal Quality Grown on Patterned Si(111) Substrate for Deep UV-LED Applications. Sci. Rep. 2016, 6, 35681. [CrossRef] [PubMed]

104. Kumagai, Y.; Akiyama, K.; Togashi, R.; Murakami, H.; Takeuchi, M.; Kinoshita, T.; Takada, K.; Aoyagi, Y.; Koukitu, A. Polarity dependence of AIN \{0001\} decomposition in flowing H-2. J. Cryst. Growth 2007, 305, 366-371. [CrossRef]

105. Takeuchi, M.; Shimizu, H.; Kajitani, R.; Kawasaki, K.; Kinoshita, T.; Takada, K.; Murakami, H.; Kumagai, Y.; Koukitu, A.; Koyama, T.; et al. Al- and N-polar AlN layers grown on c-plane sapphire substrates by modified flow-modulation MOCVD. J. Cryst. Growth 2007, 305, 360-365. [CrossRef]

106. Huang, D.; Visconti, P.; Jones, K.M.; Reshchikov, M.A.; Yun, F.; Baski, A.A.; King, T.; Morkoc, H. Dependence of GaN polarity on the parameters of the buffer layer grown by molecular beam epitaxy. Appl. Phys. Lett. 2001, 78, 4145-4147. [CrossRef]

107. Sumiya, M.; Yoshimura, K.; Ogusu, N.; Fuke, S.; Mizuno, K.; Yoshimoto, M.; Koinuma, H.; Romano, L.T.J. Effect of buffer-layer engineering on the polarity of GaN films. Vac. Sci. Technol. A 2002, 20, 456-458. [CrossRef]

108. Wu, X.H.; Fini, P.; Tarsa, E.J.; Heying, B.; Keller, S.; Mishra, U.K.; DenBaars, S.P.; Speck, J.S. Dislocation generation in GaN heteroepitaxy. J. Cryst. Growth 1998, 189, 231-243. [CrossRef]

109. Nagamatsu, K.; Okada, N.; Kato, N.; Sumii, T.; Bandoh, A.; Iwaya, M.; Kamiyama, S.; Amano, H.; Akasaki, I. Effect of c-plane sapphire misorientation on the growth of AlN by high-temperature MOVPE. Phys. Status Solidi C 2008, 5, 3048-3050. [CrossRef]

110. Okada, N.; Kato, N.; Sato, S.; Sumii, T.; Nagai, T.; Fujimoto, N.; Imura, M.; Balakrishnan, K.; Iwaya, M.; Kamiyama, S.; et al. Growth of high-quality and crack free AlN layers on sapphire substrate by multi-growth mode modification. J. Cryst. Growth 2007, 298, 349-353. [CrossRef]

111. Shen, X.Q.; Matsuhara, H.; Okumura, H. Reduction of the threading dislocation density in GaN films grown on vicinal sapphire (0001) substrates. Appl. Phys. Lett. 2005, 86, 021912. [CrossRef]

112. Shen, X.Q.; Shimizu, M.; Okumura, H. Impact of Vicinal Sapphire (0001) Substrates on the High-Quality AlN Films by Plasma-Assisted Molecular Beam Epitaxy. Jpn. J. Appl. Phys. 2003, 42, L1293-L1295. [CrossRef]

113. Hirayama, H.; Fujikawa, S.; Noguchi, N.; Norimatsu, J.; Takano, T.; Tsubaki, K.; Kamata, N. $222-282$ nm AlGaN and InAlGaN-based deep-UV LEDs fabricated on high-quality AlN on sapphire. Phys. Status Solidi A 2008, 206, 1176-1182. [CrossRef]

114. Maeda, N.; Hirayama, H. Realization of high-efficiency deep-UV LEDs using transparent p-AlGaN contact layer. Phys. Status Solidi C 2013, 10, 1521-1524. [CrossRef]

115. Zhang, Y.W.; Krishnamoorthy, S.; Johnson, J.M.; Akyol, F.; Allerman, A.; Moseley, M.W.; Armstrong, A.; Hwang, J.; Rajan, S. Interband tunneling for hole injection in III-nitride ultraviolet emitters. Appl. Phys. Lett. 2015, 141103. [CrossRef]

116. Zhang, Y.W.; Krishnamoorthy, S.; Akyol, F.; Bajaj, S.; Allerman, A.A.; Moseley, M.W.; Armstrong, A.M.; Rajan, S. Tunnel-injected sub-260nm ultraviolet light emitting diodes. Appl. Phys. Lett. 2017, 110, 201102. [CrossRef]

117. Zhang, Y.W.; Krishnamoorthy, S.; Akyol, F.; Johnson, J.M.; Allerman, A.A.; Moseley, M.W.; Armstrong, A.M.; Hwang, J.; Rajan, S. Reflective metal/semiconductor tunnel junctions for hole injection in AlGaN UV LEDs. Appl. Phys. Lett. 2017, 111, 051104. [CrossRef]

118. Verma, J.; Islam, S.M.; Protasenko, V.; Kandaswamy, P.K.; Xing, H.L.; Jena, D. Tunnel-injection quantum dot deep-ultraviolet light-emitting diodes with polarization-induced doping in III-nitride heterostructures. Appl. Phys. Lett. 2014, 104, 021105. [CrossRef] 
119. Zhao, S.; Sadaf, S.M.; Vanka, S.; Wang, Y.; Rashid, R.; Mi, Z. Sub-milliwatt AlGaN nanowire tunnel junction deep ultraviolet light emitting diodes on silicon operating at 242 nm. Appl. Phys. Lett. 2016, 109, 201106. [CrossRef]

120. Kinoshita, T.; Obata, T.; Yanagi, H.; Inoue, S. High p-type conduction in high-Al content Mg-doped AlGaN. Appl. Phys. Lett. 2013, 102, 012105. [CrossRef]

121. Kim, H.K.; Seong, T.Y.; Adesida, I.; Tang, C.W.; Lau, K.M. Low-resistance Pt/Pd/Au ohmic contacts to p-type AlGaN. Appl. Phys. Lett. 2004, 84, 1710-1712. [CrossRef]

122. Mori, K.; Takeda, K.; Kusafuka, T.; Iwaya, M.; Takeuchi, T.; Kamiyama, S.; Akasaki, I.; Amano, H. Low-ohmic-contact-resistance V-based electrode for n-type AlGaN with high AlN molar fraction. Jpn. J. Appl. Phys. 2016, 55, 05FL03. [CrossRef]

123. Katsuno, T.; Liu, Y.H.; Li, D.B.; Miyake, H.; Hiramatsu, K.; Shibata, T.; Tanaka, M. N-type conductivity control of AlGaN with high Al mole fraction. Phys. Status Solidi C 2006, 3, 1435-1438. [CrossRef]

124. Kasugai, H.; Miyake, Y.; Honshio, A.; Mishima, S.; Kawashima, T.; Iida, K.; Iwaya, M.; Kamiyama, S.; Amano, H.; Akasaki, I.; et al. High-efficiency nitride-based light-emitting diodes with moth-eye structure. Jpn. J. Appl. Phys. 2005, 44, 7414-7417. [CrossRef]

125. Brunner, D.; Angerer, H.; Bustarret, E.; Freudenberg, F.; Hopler, R.; Dimitrov, R.; Ambacher, O.; Stutzmann, M. Optical constants of epitaxial AlGaN films and their temperature dependence. J. Appl. Phys. 1997, 82, 5090-5096. [CrossRef]

126. Amano, H.; Kamiyama, S.; Kim, M.; Pernot, C.; Hirano, A. Method of Producing Template for Epitaxial Growth Having a Sapphire (0001) Substrate, an Initial-Stage AlN Layer and Laterally Overgrown AlxGa1-xN (0001) Layer. PCT/JP2009/071541. U.S. Patent 8,659,031, 7 June 2010.

127. Home Page of Nikkiso Co., Ltd. Available online: https://www.nikkiso.co.jp/technology/project/duv-led. html (accessed on 3 April 2018).

128. Tsujishita, M.; Hirano, A. Two-dimensional quenching lifetime measurement of $\mathrm{OH}: \mathrm{A}_{2} \Sigma^{+}\left(\mathrm{v}^{\prime}=1\right)$ and NO: $\mathrm{A}_{2} \Sigma^{+}\left(\mathrm{v}^{\prime}=0\right)$ in atmospheric-pressure flames. Appl. Phys. B 1996, 62, 255-262. [CrossRef]

129. Yoshida, H.; Kuwabara, M.; Yamashita, Y.; Uchiyama, K.; Kan, H. Radiative and nonradiative recombination in an ultraviolet GaN/AlGaN multiple-quantum-well laser diode. Appl. Phys. Lett. 2010, 96, 211122. [CrossRef]

130. Mickevicius, J.; Jurkevicius, J.; Tamulaitis, G.; Shur, M.S.; Shatalov, M.; Yang, J.W.; Gaska, R. Influence of carrier localization on high-carrier-density effects in AlGaN quantum wells. Opt. Express 2014, 22, A491-A497. [CrossRef] [PubMed]

131. Hirano, A.; Nagasawa, Y.; Ippommatsu, M.; Aosaki, K.; Honda, Y.; Amano, H.; Akasaki, I. Development of AlGaN-based deep-ultraviolet (DUV) LEDs focusing on the fluorine resin encapsulation and the prospect of the practical applications. Proc. SPIE 2016, 9926, 99260C. [CrossRef]

132. Bhattacharyya, A.; Moustakas, T.D.; Zhou, L.; Smith, D.J.; Hug, W. Deep ultraviolet emitting AlGaN quantum wells with high internal quantum efficiency. Appl. Phys. Lett. 2009, 99, 181907. [CrossRef]

133. Shatalov, M.; Yang, J.W.; Sun, W.H.; Kennedy, R.; Gaska, R.; Liu, K.; Shur, M.; Tamulaitis, G. Efficiency of light emission in high aluminum content AlGaN quantum wells. J. Appl. Phys. 2009, 105, 073103. [CrossRef]

134. Banal, R.G.; Funato, M.; Kawakami, Y. Extremely high internal quantum efficiencies from AlGaN/AlN quantum wells emitting in the deep ultraviolet spectral region. Appl. Phys. Lett. 2011, 99, 011902. [CrossRef]

135. Banal, R.G.; Funato, M.; Kawakami, Y. Characteristics of high Al-content AlGaN/AlN quantum wells fabricated by modified migration enhanced epitaxy. Phys. Status Solidi C 2010, 7, 7-8. [CrossRef]

136. Funato, M.; Kawakami, Y.; Kyoto University, Japan. Personal communication, 2017.

137. Bryan, Z.; Bryan, I.; Mita, S.; Tweedie, J.; Sitar, Z.; Collazo, R. Strain dependence on polarization properties of AlGaN and AlGaN-based ultraviolet lasers grown on AlN substrates. Appl. Phys. Lett. 2015, 106, 232101. [CrossRef]

138. Kataoka, K.; Funato, M.; Kawakami, Y. Development of polychromatic ultraviolet light-emitting diodes based on three-dimensional AlGaN quantum wells. Appl. Phys. Express 2017, 10, 212001. [CrossRef]

139. Yamada, K.; Nagasawa, Y.; Nagai, S.; Hirano, A.; Ippommatsu, M.; Aosaki, K.; Honda, Y.; Amano, H.; Akasaki, I. Study on the Main-Chain Structure of Amorphous Fluorine Resins for Encapsulating AlGaN-Based DUV-LEDs. Phys. Status Solidi A 2018, 1700525. [CrossRef]

140. Nam, K.B.; Li, J.; Nakarmi, M.L.; Lin, J.Y.; Jiang, H.X. Unique optical properties of AlGaN alloys and related ultraviolet emitters. Appl. Phys. Lett. 2004, 84, 5254-5266. [CrossRef] 
141. Taniyasu, Y.; Kasu, M. Polarization property of deep-ultraviolet light emission from C-plane AlN/GaN short-period superlattices. Appl. Phys. Lett. 2011, 99, 251112. [CrossRef]

142. Zhang, J.; Zhao, H.P.; Tansu, N. Large optical gain AlGaN-delta-GaN quantum wells laser active regions in mid-and deep-ultraviolet spectral regimes. Appl. Phys. Lett. 2011, 98, 171111. [CrossRef]

143. Xie, J.Q.; Mita, S.; Bryan, Z.; Guo, W.; Hussey, L.; Moody, B.; Schlesser, R.; Kirste, R.; Gerhold, M.; Collazo, R.; Sitar, Z. Lasing and longitudinal cavity modes in photo-pumped deep ultraviolet AlGaN heterostructures. Appl. Phys. Lett. 2013, 102, 171102. [CrossRef]

144. Li, X.H.; Kao, T.T.; Satter, M.M.; Wei, Y.O.; Wang, S.; Xie, H.E.; Shen, S.C.; Yoder, P.D.; Fischer, A.M.; Ponce, F.A.; et al. Demonstration of transverse-magnetic deep-ultraviolet stimulated emission from AlGaN multiple-quantum-well lasers grown on a sapphire substrate. Appl. Phys. Lett. 2015, 106. [CrossRef]

145. Lachab, M.; Sun, W.H.; Jain, R.; Dobrinsky, A.; Gaevski, M.; Rumyantsev, S.; Shur, M.; Shatalov, M. Optical polarization control of photo-pumped stimulated emissions at $238 \mathrm{~nm}$ from AlGaN multiple-quantum-well laser structures on AlN substrates. Appl. Phys. Express 2017, 10, 012702. [CrossRef]

146. Djavid, M.; Mi, Z.T. Enhancing the light extraction efficiency of AlGaN deep ultraviolet light emitting diodes by using nanowire structures. Appl. Phys. Lett. 2016, 108, 051102. [CrossRef]

147. Islam, S.M.; Protasenko, V.; Rouvimov, S.; Xing, H.; Jena, D. Sub-230nm deep-UV emission from GaN quantum disks in AlN grown by a modified Stranski-Krastanov mode. Jpn. J. Appl. Phys. 2016, 55, 05 FF06. [CrossRef]

148. Islam, S.M.; Lee, K.V.; Verma, J.; Protasenko, V.; Rouvimov, S.; Bharadwaj, S.; Xing, H.; Jena, D. MBE-grown 232-270nm deep-UV LEDs using monolayer thin binary GaN/AlN quantum heterostructures. Appl. Phys. Lett. 2017, 110, 041108. [CrossRef]

149. Islam, S.M.; Protasenko, V.; Lee, K.; Rouvimov, S.; Verma, J.; Xing, H.L.; Jena, D. Deep-UV emission at 219 $\mathrm{nm}$ from ultrathin MBE GaN/AlN quantum heterostructures. Appl. Phys. Lett. 2017, 111, 091104. [CrossRef]

150. Hirano, A. Tanpacho shigaisen LED no jitsuyouka ni tomonau oyotenkai no tenboh. Hikari Alliance 2017, 28, 54-59. (In Japanese)

(C) 2018 by the authors. Licensee MDPI, Basel, Switzerland. This article is an open access article distributed under the terms and conditions of the Creative Commons Attribution (CC BY) license (http:/ / creativecommons.org/licenses/by/4.0/). 